CENTRO UNIVERSITÁRIO DA FEI

RODRIGO GALUZZI GARCIA PIVA

AUXÍLIO NO DIAGNÓSTICO EM EXAMES DE ESPIROMETRIA COM A APLICAÇÃO DAS WAVELETS

São Bernardo do Campo 
RODRIGO GALUZZI GARCIA PIVA

\section{AUXÍLIO NO DIAGNÓSTICO EM EXAMES DE ESPIROMETRIA COM A APLICAÇÃO DAS WAVELETS}

Dissertação de Mestrado apresentada ao Centro Universitário da FEI para obtenção do título de Mestre em Engenharia Elétrica, orientado pelo Prof. Dr. Aldo Artur Belardi.

São Bernardo do Campo 
Galuzzi Garcia Piva, Rodrigo.

Auxílio no diagnóstico em exames de espirometria com a aplicação das wavelets / Rodrigo Galuzzi Garcia Piva.

São Bernardo do Campo, 2017.

76 f. : il.

Dissertação - Centro Universitário FEI.

Orientador: Prof. Dr. Aldo Artur Belardi.

1. Wavelets. 2. Espirometria. 3. Estatística Aplicada. I. Artur Belardi, Aldo, orient. II. Título.

Elaborada pelo sistema de geração automática de ficha catalográfica da FEI com os dados fornecidos pelo(a) autor(a). 
Título do Trabalho: Auxílio no diagnóstico em exames de espirometria com a aplicação das wavelets.

Área de Concentração: Processamento de Sinais

Orientador: Prof. Dr. Aldo Artur Belardi

Data da realização da defesa: 31/03/2017

\section{ORIGINAL ASSINADA}

Avaliação da Banca Examinadora:

São Bernardo do Campo, 31 / 03 / 2017.

\section{MEMBROS DA BANCA EXAMINADORA}

Prof. Dr. Aldo Artur Belardi

Prof. Dr. Luiz Antonio Celiberto Júnior

Prof. Dr. Marco Antonio Assis de Melo
Ass. :

Ass.:

Ass. :

A Banca Julgadora acima-assinada atribuiu ao aluno o seguinte resultado:

APROVADO $\bigotimes \quad$ REPROVADO

\section{VERSÃO FINAL DA DISSERTAÇÃO}

APROVO A VERSÃO FINAL DA DISSERTAÇÃO EM QUE FORAM INCLUÍDAS AS RECOMENDAÇÕES DA BANCA EXAMINADORA
Aprovação do Coordenador do Programa de Pós-graduação

Prof. Dr. Carlos Eduardo Thomaz 
A minha família. 


\section{AGRADECIMENTOS}

A Deus por me amparar nos momentos difíceis, me dar força interior para superar as dificuldades, mostrar o caminho nas horas incertas e me suprir em todas as minhas necessidades.

A meu pai, Alcides Aparecido Piva, que hoje sei o homem forte que é, que me ensinou a ser uma pessoa honesta, trabalhadora, dedicada a família e a ter a honra como maior princípio.

A minha mãe, Tânia Galuzzi Garcia, que sempre me deu o suporte nas minhas necessidades, sempre me amparou e sempre disponível com uma palavra de conforto.

A minha amada esposa Elâine de Araújo Piva, que sempre esteve do meu lado em todos os momentos, bons e ruins, e nunca deixou de me amparar.

Ao Prof. Dr. Aldo Artur Belardi, por acreditar em mim, me mostrando o caminho da ciência.

A minha família, a qual amo muito, pelo carinho, paciência e incentivo.

Aos amigos que fizeram parte desses momentos sempre me ajudando e incentivando.

A todos os companheiros de ensino desta instituição, Fundação de Estudo Inaciana, em especial a Douglas de Rizzo Meneghetti.

Aos colegas durante esse estudo, que se tornaram amigos, Renato Gomes Barelli, Rodrigo Prior Bechelli e David Penoff Júnior.

A todos os colegas e professores da pós-graduação em Engenharia Elétrica pelo convívio e aprendizado.

Ao Engenheiro Dorival Sortino, por acreditar em mim e permitir que eu tivesse ingressado nos estudos de Engenharia.

Ao Dr. Jackson Gomes Marques, que possibilitou a execução deste estudo através do fornecimentos da base de dados de exames realizados. 
“A Adversidade É A Pedra Onde Eu Afio A Minha Espada"

Ms. Burns, 2006 


\section{RESUMO}

Em diversas áreas da pesquisa, temos visto a utilização de wavelets, com o intuito de permitir o modelamento matemático, proporcionando uma melhor análise de sinais mais acurada, com uma pequena margem de erro, criando uma alternativa de caracterizar uma forma de onda mais flexível no domínio do tempo, frequência e amplitude.

No campo da saúde principalmente na área de espirometria, tanto na área de diagnóstico quanto no tratamento, identificamos diversos estudos utilizando métodos numéricos, que permitem identificar se o paciente é saudável ou possui alguma enfermidade.

Uma das áreas da medicina que cuida do sistema respiratório, conhecida como pneumologia, também tem sido alvo de pesquisas utilizando métodos numéricos. Um dos exames possíveis nesse segmento é a prova de função pulmonar, conhecida como espirometria, que é a medição do ar que entra e sai dos pulmões. Este exame pode ser realizado através de manobras expiratórias forçadas ou durante uma respiração lenta, auxiliando na prevenção e diagnóstico além da quantificação dos distúrbios ventilatórios.

É um exame que exige uma compreensão e cooperação do paciente, que é realizado através de um equipamento específico com técnicas padronizadas além de profissionais capacitados.

O resultado obtido através deste teste é comparado com amostras da população previamente avaliadas e a sua interpretação deve ser feita considerando os dados clínicos e epidemiológicos.

A proposta de nosso estudo foi analisar os resultados estatísticos de uma série de curvas de espirometria, e através da aplicação das wavelets, compará-los com os resultados previamente conhecidos classificando em normal, obstrutivo e restritivo, com a possibilidade de auxiliar no laudo médico e um diagnóstico mais confiável.

Com a implementação da metodologia proposta e dos resultados obtidos verificamos que podemos auxiliar no resultado para que o paciente tenha o diagnóstico de uma determinada enfermidade, contribuindo no desenvolvimento de um sistema de interpretação confiável auxiliando no diagnóstico dos exames, através da aplicação de wavelets nas curvas de espirometria.

Palavras-chave: Wavelets. Espirometria. Estatística Aplicada. 


\begin{abstract}
In several areas of research, we have seen the use of wavelets in order to allow mathematical modeling, providing a better accurate signal analysis with a small margin of error, creating an alternative to characterize a more flexible waveform in the time, frequency and amplitude domain.

In the field of health, especially in the area of spirometry, both in diagnosis and treatment, we have identified several studies using numerical methods that allow us to identify if the patient is healthy or has some disease.

One of the areas of medicine that takes care of the respiratory system, known as pneumology, has also been the subject of research using numerical methods. One of the possible tests in this segment is the pulmonary function test, known as spirometry, which is the measurement of air entering and exiting the lungs. This exam may be performed through forced expiratory maneuvers or during slow breathing, assisting in prevention and diagnosis in addition to the quantification of ventilatory disorders.

It is an exam that requires an understanding and cooperation of the patient, which is performed through a specific equipment with standardized techniques in addition to trained professionals.

The result obtained through this test is compared with samples from the population previously evaluated and their interpretation must be made considering the clinical and epidemiological data.

The purpose of our study was to analyze the statistical results of a series of spirometry curves and, through the application of the wavelets, to compare them with previously known results classified as normal, obstructive and restrictive, with the possibility of assisting in the medical report and a more reliable diagnosis.

With the implementation of the proposed methodology and the results obtained we verified that we can help in the result so that the patient has the diagnosis of a certain disease, contributing in the development of a reliable interpretation system helping in the exams diagnosis through the application of wavelets in the curves of spirometry.
\end{abstract}

Keywords: Wavelets. Spirometer. Applied Statistics. 


\section{LISTA DE ILUSTRAÇÕES}

Ilustração 1 - Brônquios Pulmonares ． . . . . . . . . . . . . . . . . . . . 20

Ilustração 2 - Brônquios Pulmonares em Destaque . . . . . . . . . . . . . . . . . 21

Ilustração 3 - Bronquíolos Pulmonares em Destaque . . . . . . . . . . . . . . . . . 22

Ilustração 4 - Alvéolos Pulmonares . . . . . . . . . . . . . . . . . . . 23

Ilustração 5 - Pulmão Vista Lateral . . . . . . . . . . . . . . . . . . . . . . . 24

Ilustração 6 - Pulmão Vista Frontal . . . . . . . . . . . . . . . . . . . 25

Ilustração 7 - Exame de espirometria . . . . . . . . . . . . . . . . . . . . 26

Ilustração 8 - Formatos da Curva Fluxo x Volume . . . . . . . . . . . . . . . . . 27

Ilustração 9 - Espirômetro SpiroBank . . . . . . . . . . . . . . . . . . . . . . . 29

Ilustração 10-Espirômetro Sensor Medics . . . . . . . . . . . . . . . . . . . . . . . . . 29

Ilustração 11 -Espirômetro Easy One ～. . . . . . . . . . . . . . . . . . . . . 30

Ilustração 12 -Espirômetro Koko - PFT ～. . . . . . . . . . . . . . . . . . 30

Ilustração 13 -Espirometro VMax2 . . . . . . . . . . . . . . . . . . . . 31

Ilustração 14-Espirometro Collins CPL . . . . . . . . . . . . . . . . . . . . . 32

Ilustração 15 -Wavelet de HAAR . . . . . . . . . . . . . . . . . . . . . . . . . 34

Ilustração 16-Wavelet de Meyer . . . . . . . . . . . . . . . . . . . . . . 34

Ilustração 17 -Wavelet de Battle-Lemarié ． . . . . . . . . . . . . . . . . . 35

Ilustração 18 - Wavelet Chapéu Mexicano . . . . . . . . . . . . . . . . . . . . . . . 35

Ilustração 19-Wavelet de Shannon . . . . . . . . . . . . . . . . . . . . . 36

Ilustração 20 - Inicio da Extração dos valores . . . . . . . . . . . . . . . . . . . 37

Ilustração 21 -Extração dos valores . . . . . . . . . . . . . . . . . . . . 37

Ilustração 22 -Exportação dos valores . . . . . . . . . . . . . . . . . . . . 38

Ilustração 23 -Importação do Dados no Matlab . . . . . . . . . . . . . . . . . . . . 39

Ilustração 24 -Importação do Dados . . . . . . . . . . . . . . . . . . . . . . . 39

Ilustração 25 -Coeficientes de Detalhes . . . . . . . . . . . . . . . . . . . . 40

Ilustração 26 -Importação do Dados no Matlab . . . . . . . . . . . . . . . . . . . . . . 40

Ilustração 27 -Previsto da Persona Sexo Masculino . . . . . . . . . . . . . . . . . . . . 41

Ilustração 28 - Previsto da Persona Sexo Feminino . . . . . . . . . . . . . . . . . . . . . 42

Ilustração 29-Curvas dos Pacientes Normais . . . . . . . . . . . . . . . . . . . . . . 42

Ilustração 30-Curvas dos Pacientes Obstrutivos . . . . . . . . . . . . . . . . . . 43

Ilustração 31 -Curvas dos Pacientes Restritivos . . . . . . . . . . . . . . . . . . 43

Ilustração 32 -Curvas dos Pacientes Conforme Covariância . . . . . . . . . . . . . . . . 43

Ilustração 33 -Coeficientes dos dados de $\mathrm{C} 1 \ldots \ldots$. . . . . . . . . . . . . 45

Ilustração 34 -Coeficientes dos dados de C25 . . . . . . . . . . . . . . . . 45

Ilustração 35 -Coeficientes dos dados de C42 . . . . . . . . . . . . . . . . . . 46

Ilustração 36-Covariancia Sexo Masculino . . . . . . . . . . . . . . . . . . . 46

Ilustração 37 -Covariancia Sexo Feminino . . . . . . . . . . . . . . . . . . . . . . . . . 47 
Ilustração 38 -Método de Diagnóstico na Espirometria . . . . . . . . . . . . . . . . . 48

Ilustração 39-Tela do Software do Equipamento do Estudo de Caso . . . . . . . . . . . 49

Ilustração 40 - Tela do Laudo do Equipamento do Estudo de Caso . . . . . . . . . . . . 50

Ilustração 41 -Exportação dos Valores do Exame . . . . . . . . . . . . . . . . . 50

Ilustração 42 -Preparação para aplicação das wavelets . . . . . . . . . . . . . . . . 50

Ilustração 43 -Dados Exportados Comentados . . . . . . . . . . . . . . . . . . . . 70 


\section{LISTA DE TABELAS}

Tabela 1 - Tabela do resultados de dados obtidos antes da aplicação das wavelets . . . . 52

Tabela 2 - Valores obtidos após a aplicação de Wavelets de Meyer . . . . . . . . . . 53

Tabela 3 - Valores de covariância e desvio padrão obtidos . . . . . . . . . . . . . . 54

Tabela 4 - Tabela de Resultados Médios para Validação . . . . . . . . . . . . . . 54 
$\psi_{a, b}(x)$ "Wavelet" mãe.

$\psi_{j, k}^{(H)}(x)$ "Wavelet" Pai

$f(\omega)$ "Wavelets" de Meyer

$\psi^{(H)}(x)$ "Wavelet" de Haar.

$\varphi^{(H)}(x)$ Função escala para a "Wavelet" de Battle - Lemrié.

STPD - Condições padrão, temperatura 0 Graus Celsius, pressão 760mmHg,a seco.

BTPS - Condições corporais de temperatura, pressão ambiente, saturada.

ATPD - Temperatura e pressão ambientais, a seco.

ATPS - Temperatura e pressão ambientais, saturada com vapor d'água.

VR - Volume residual

VRE - Volume de reserva expiratória

VC - Volume corrente

CV - Capacidade vital

CI - Capacidade inspiratória

$\mathrm{CRF}$ - Capacidade residual funcional

CPT - Capacidade pulmonar total

CVI - Capacidade vital inspiratória

CVF - Capacidade vital forçada

CVFI - Capacidade vital forçada inspiratória

VEFt - Volume expiratório forçado

VEFt/CVFIo - Razão entre volume expiratório forçado e capacidade vital forçada.

FEFx-yIo - Fluxo expiratório forçado médio de um segmento da manobra de CVF.

FEFxIo - Fluxo expiratório forçado numa percentagem de volume da CVF.

PFE- Pico de fluxo expiratório.

TEF - Tempo de expiração forçada. 


\section{SUMÁRIO}

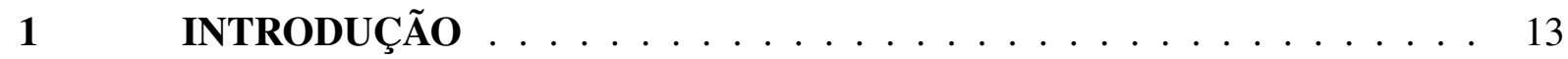

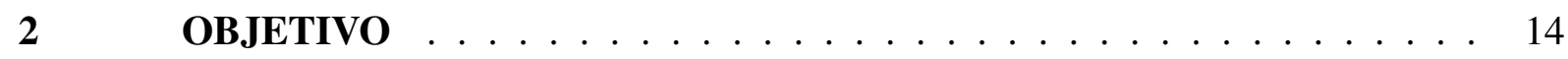

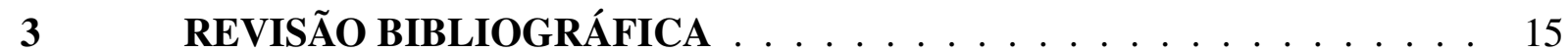

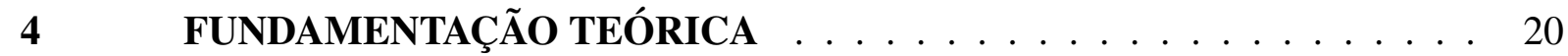

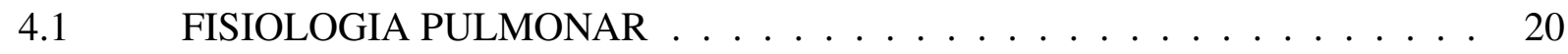

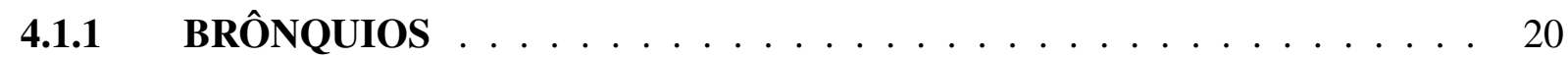

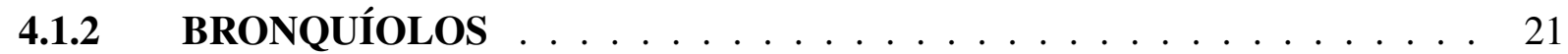

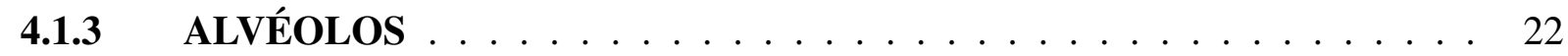

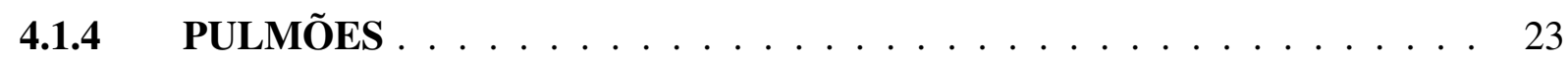

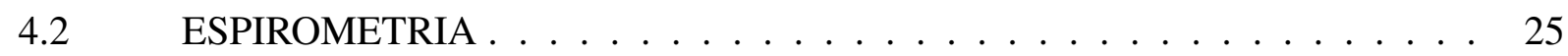

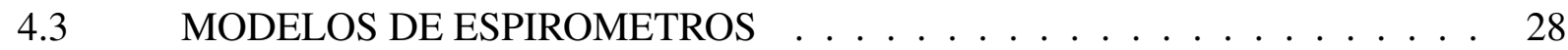

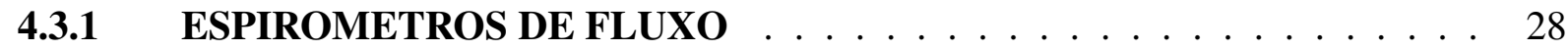

4.3.1.1 MIR ESPIROBANK . . . . . . . . . . . . . . . . . . . . . . . 29

4.3.1.2 SENSOR MEDICS M5000 _ . . . . . . . . . . . . . . . . . . . . . . 29

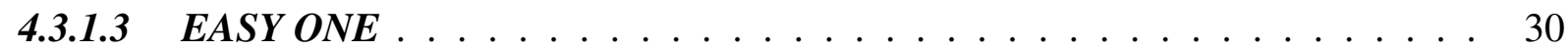

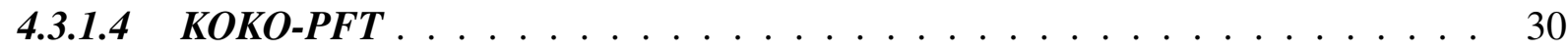

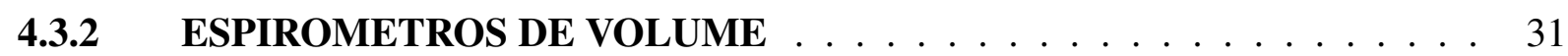

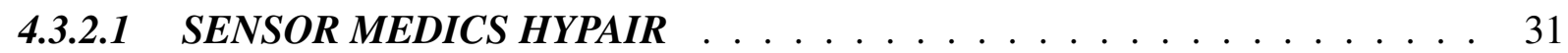

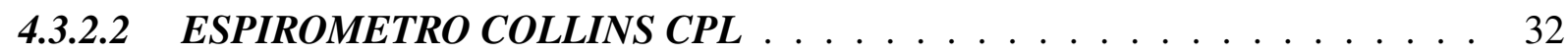

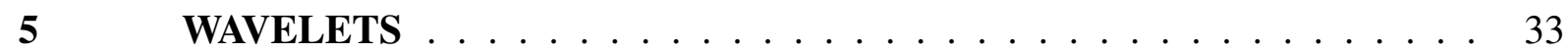

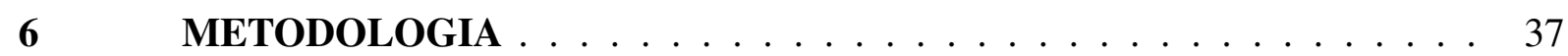

$7 \quad$ RESULTADOS OBTIDOS $\ldots \ldots \ldots \ldots \ldots \ldots \ldots$

7.1 DADOS UTILIZADOS $\ldots \ldots \ldots \ldots \ldots \ldots \ldots$

7.2 AVALIAÇÃO DA APLICAÇÃO DE WAVELETS $\ldots \ldots \ldots \ldots \ldots$

7.3 DISCUSSÕES SOBRE A METODOLOGIA . . . . . . . . . . . . . . . . 48

7.4 ESTUDO DE CASO . . . . . . . . . . . . . . . . . . . . . 49

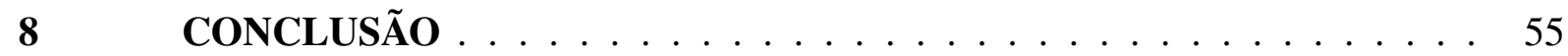

8.1 TRABALHOS FUTUROS $\ldots \ldots \ldots \ldots \ldots \ldots \ldots$

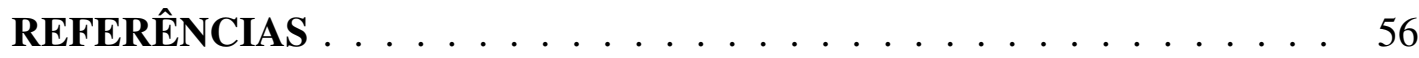

APÊNDICE A - Algoritmo de Utilização para Inserção Dos Dados no Ma-

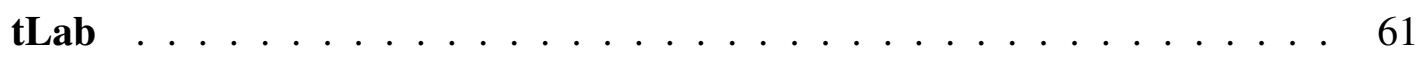

APÊNDICE B - Dados Exportados Comentados . . . . . . . . . . . . . . 69

APÊNDICE C - Autorização do Uso de Base de Dados . . . . . . . . . . 71 


\section{INTRODUÇÃO}

Estudos referentes a classificação de resultados de exames na área de pneumologia, que é a área da medicina que estuda o comportamento dinâmico do funcionamento dos pulmões e vias aéreas, em sua maioria, aplicou-se algum tipo de cálculo matemático a fim de relacionar os resultados do paciente com outros na mesma população local, e também com o intuito de levantar os parâmetros necessários para se efetuar um laudo médico confiável.

Também foi utilizado um modelo matemático para se obter parâmetros onde o paciente é considerado dentro da normalidade, na área de pneumologia. Para essa população onde o paciente se encontra, os valores que utiliza-se como parâmetro para classificar os resultados encontrados é chamado predito, ou previsto, e vários estudos mostram a intenção de procurar ter o parâmetro mais confiável possível, interligando os modelos matemáticos de interpretação que resultam em basicamente classificar o paciente em três diferentes tipos: normal, obstrutivo e restritivo (C. A. C. PEREIRA, 1996).

Em nossa pesquisa verificamos que diversos estudiosos aplicaram um sistema pontual de valores dentro de um espaço amostral dos pacientes, ou seja, através de diversos exames os médicos e pesquisadores coletavam o valor da CVF (Capacidade Vital Forçada) por exemplo, ou o VEF (Volume Expiratório Forçado) que é um valor único de cada exame. Os estudos são realizados em sua maioria utilizando este único valor de cada exame realizado, a partir de um espaço amostral com alguns voluntários, e aplicando-se um determinado modelamento matemático, chegam a uma conclusão. Já em nosso trabalho pretendemos executar uma análise numérica com todas as medidas encontradas em um exame de função pulmonar, através da aplicação de métodos numéricos avançados, não considerando a demonstração ou modelamento matemático de equações.

O mesmo caso aplica-se na área de pneumologia, pois diversas variáveis podem influ-

enciar no resultado do exame, como apresentaremos nos capítulos a seguir. É um exame que sofre interferência de diversas variáveis, entre elas uma das mais importantes na execução da manobra expiratória é a dependência da disposição do paciente que irá realizar esta manobra. $\mathrm{O}$ diagnóstico médico por diversas vezes é realizado de forma visual, contando com a experiência médica e colaboração do paciente.

Assim, analisamos a curva característica da prova de função pulmonar, extraindo os valores de coordenadas de fluxo em função do volume dos exames, em um espaço amostral de 60 exames realizados, com autorização do Dr. Jackson Gomes Marques conforme anexo A. e interligamos o aplicativo Matlab em conjunto com as wavelets por fim analisando estatisticamente os pacientes amostrados analisando os coeficientes de detalhes caracterizando-os como normal, restritivo ou obstrutivo. 


\section{OBJETIVO}

Iremos analisar os gráficos resultantes de um conjunto de exames de prova de função pulmonar e, através da aplicação de wavelets, obtermos coeficientes de detalhes para auxiliar na interpretação dos resultados dos exames de pneumologia, conhecidas como espirometria (SPRIGGS, 1978).

A partir do conjunto de resultados dos exames de função pulmonar, extraímos as curvas de cada exame para realizar a análise estatística, através do software do próprio equipamento. Estes dados foram exportados para o aplicativo matlab e processados utilizando o toolbox das wavelets.

Desta forma, através da análise do desvio padrão e covariância conseguimos estabelecer uma relação entre normalidade e enfermidade, classificando os exames de espirometria em normal, restritivo ou obstrutivo (C. A. C. PEREIRA, 1996).

Optamos pelo uso das wavelets pois através da variação de frequência e da amplitude podemos relacionar uma matriz formada por coeficientes que permite através de sua análise classificar a função pulmonar.

Em diversos segmentos da área médica, quando é realizado um exame, deseja-se obter um determinado diagnóstico. Seu resultado é comparado com outros exames já realizados, onde valores de referência e diagnóstico são conhecidos. Por exemplo, no exame de glicemia o resultado deve estar numa faixa pré determinada entre adultos para ser considerado normal. Essa referência numérica em determinada população já previamente estudada auxilia o profissional, garantindo um laudo médico confiável para aquele paciente. No exame de espirometria, um paciente obeso pode apresentar características de obstrução e na realidade ser saudável, podendo ocasionar um falso diagnóstico, mesmo utilizando valores numéricos previamente conhecidos de referência.

Então, através deste estudo e metodologia auxiliamos no método de interpretação dos resultados do exame de prova de função pulmonar, possibilitando o aperfeiçoamento dos exames de espirometria.

Na pesquisa realizada, não encontramos estudos que utilizam todos os valores provenientes das curvas gráficas que são obtidas na prova de função pulmonar, mas apenas alguns de seus valores, conhecido como previstos, onde o resultado em determinada população é usado como método comparativo.

Com a aplicação da metodologia proposta observamos que existe uma melhora nas condições de interpretação, pois foi possível um resultado aprimorado com um biomarcador adicional, além de gerar uma segurança maior no diagnóstico do paciente pelo profissional da saúde. 


\section{REVISÃO BIBLIOGRÁFICA}

Uma área que vem sendo muito estudada, devido ao envelhecimento mundial, adicionando também novos resultados de pesquisas sobre o tabagismo, câncer de pulmão, enfisema pulmonar e principalmente a asma, é a área médica de pneumologia, onde o principal exame realizado é a prova de função pulmonar, conhecida por espirometria. Para realizar este exame, o médico utiliza um equipamento conhecido como espirômetro, que faz a análise do volume expirado e inspirado pelo paciente e a partir destes dados executa uma série de cálculos numéricos para se obter um resultado de como está a saúde pulmonar da pessoa. Temos relatos desde a época do ano de 1700 que o ser humano tenta obter dados da capacidade pulmonar de seu sistema respiratório, como retratado em (SPRIGGS, 1978).

(HANKINSON; GARDNER, 1982), com o intuito de testar e qualificar espirômetros, selecionou um conjunto de vinte e quatro formas de onda, a partir de um conjunto maior de manobras de capacidade vital forçada. Foram realizadas por pacientes que possuem uma grande diversificação de anormalidades, obtendo seus resultados. Parâmetros da espirometria foram obtidos em cada modelo de forma de onda; e por conseguinte, as exigências de desempenho puderam ser facilmente estabelecidas. Estas formas de onda padronizadas foram inseridas em vários softwares de espirometria e usadas para avaliar o equipamento, através da calibração por uma seringa mecânica de três litros. Essa calibração é usada na rotina diária de exames de espirometria, realizando o teste do software que executa este exame. Dessa sua pesquisa resulta o padrão de normalidade utilizado desde 1982 em pacientes americanos.

Estudando a pesquisa de (FINKELSTEIN et al., 1995), percebemos a importância do exame de espirometria também na área de transplantes, pois foi possível perceber que existe uma diferença significativa nos resultados do exames de espirometria em alguns resultados que podem ser usados como marcadores de uma possível rejeição do orgão transplantado.

Conforme descrito em (AKAY, 1997), é mostrado a aplicação de wavelets na área de biomedicina, mostrando que os resultados tem sido satisfatórios em análise de sinais e detecção prematura de artefatos em exames de diagnóstico por imagem. É também descrito neste estudo qual seria o avanço e em que segmentos este modelo matemático seria utilizado.

Em (COSTA; JARNARNI, 2001), é realizado um estudo que verifica métodos de diagnósticos em exames de espirometria, estabelecendo parâmetros para realizar uma interpretação confiável, formato ainda utilizado atualmente.

(RODRIGUES; Carlos A.C. PEREIRA, 2001), mostra a resposta em exames de espirometria com o uso do bronco dilatador, demonstrando em seus resultados que não ocorreu diferença significativa em alguns parâmetros utilizados no diagnóstico de patologias pulmonares, mas sim em outros valores que geralmente não são interpretados.

Em (LADOSKY et al., 2001) é comparado os valores encontrados no exame de espirometria em previstos diferentes, mostrando que esses valores dependem basicamente do local onde está sendo realizado o exame (população local) e não do previsto utilizado. 
As wavelets vem sendo aplicadas na área médica, como em (ADELI; ZHOU; DADMEHR, 2003), que utiliza as transformadas de wavelets a fim de analisar pacientes com epilepsia. Ele se utilizou de um método para decompor os dados de frequências de picos de EEG de 3(Hz) Hertz, e fazendo do uso do modelo de Daubechies, observou que seria necessário realizar um estudo com maior profundidade, pois a ideia inicial era predizer se o paciente poderia ter uma crise epilética ou não.

No estudo de (AKPINAR-ELCI; FEDAN; P. L. ENRIGHT, 2006), é mostrado o quanto é difundido e utilizado o exame de função pulmonar, além de mostrar o quão importante é a compreensão do paciente na execução do exame. Pacientes obstrutivos por algumas vezes não realizam a manobra expiratória dentro dos valores de tempo aceitáveis, gerando uma frustração em não realizar o exame, tanto pelo técnico quanto ao próprio paciente. Assim, este tipo de situação colabora com erros no estudo, devido ao uso de testes de má qualidade nas amostras. Então em seu estudo propõe o uso da variável VEF6 como critério de classificação em patologias pulmonares.

Então, de acordo com (FERRARI; HOTO; MACULAN, 2006), que utilizou quatro sistemas de redes neurais a fim de determinar se o paciente possui doença pulmonar obstrutiva crônica; baseando-se em vários métodos classificadores entre eles as wavelets, obteve uma possibilidade de predizer se o paciente possui tal enfermidade, utilizando um único valor do exame, a CVF.

Conforme mostrado em (CARTA et al., 2007) que realiza um comparativo entre leituras espirométricas de pressão diferencial e pressão linear, obtendo resultados satisfatórios nos dois casos, ou seja, os valores são próximos entre si.

No estudo de (KALICKA; SLOMINSKI; KUZIEMSKI, 2008), tentaram modelar a curva de espirometria através do método de regressão matemática não linear, obtendo sucesso em tal caracterização.

De acordo com (PINHEIRO et al., 2009), que comparou os valores do previsto brasileiro com os sugeridos pela Global Lung Function Initiative 2012, alguns parâmetros utilizados para diagnóstico obtiveram valores diferentes, alertando sobre a escolha correta para realizar o exame.

Em (BUSHA, 2010) obteve-se resultados através da aplicação de filtros em cálculos com wavelets com o objetivo de parametrizar as variâncias cardíacas no paciente.

Assim verificamos também que em (SAHIN et al., 2010) apresenta o uso de máquinas de suporte vetorial multiclasse (SVMs) para o diagnóstico de padrões de espirometria (normal, restritivo, obstrutivos). As decisões SVM foram fundidas utilizando códigos de correção de erros (CRC). O SVM multiclasse juntamente com o CRC foi treinado em três parâmetros de espirometria (volume expiratório forçado em 1s-VEF1, capacidade vital forçada - CVF e razão FEV1/FVC). A precisão total de classificação da SVM foi de $97,32 \%$. Os resultados obtidos confirmaram a validade das SVM para ajudar na tomada de decisão clínica. 
Como em (KAVITHA; SUJATHA; RAMAKRISHNAN, 2010), diversos algoritmos tem sido estudado com o intuito de estabelecer padrões de normalidade, neste caso diagnosticar obstrução de vias aéreas através da máquina de suporte vetorial.

Conforme estudado em (LAY-EKUAKILLE; VENDRAMIN; TROTTA, 2010), é possível recriar a curva espirométrica, utilizando coeficientes de equações matemáticas não lineares, onde neste estudo utilizaram um algoritmo conhecido como CGA, ou "controlled genetic algorithm". Conclui-se que é possível a utilização de cálculos matemáticos em curvas de espirometria.

(AL-NAAMI et al., 2010), utilizou as wavelets para detectar e definir uma divisão no batimento cardíaco em pacientes, que é considerado como um alerta patológico da saúde coronária. Seus resultados expressaram valores acima de noventa por cento de resultado e precisão neste tipo de diagnóstico.

Através de processamento matemático, foi possível predizer as condições de saúde em transplantados pulmonares, como descrito em (WANG, 2011). No campo de caracterização de pacientes puderam estabelecer padrões de reconhecimento de valores baseando-se nos valores do volume expiratório pulmonar dos pacientes (VEF).

Verificamos que em (DESHMUKH; PANDITRAO, 2012) é descrito um método para a construção de um espirômetro baseado em um termistor que esfria de acordo com o fluxo que passa por ele. Conseguiram obter resultados satisfatórios pelo fato de conseguir visualizar a curva espirométrica e também se o paciente tossiu durante o exame.

(J. KHUBANI, 2012), estabeleceu parâmetros para se prever o reconhecimento de padrões utilizando a máquina de suporte vetorial a fim de auxiliar nas investigações em espirometria. A máquina de suporte vetorial constrói um hiperplano ou conjunto de hiperplanos em um espaço tridimensional, que pode ser usado para a classificação ou outras tarefas, reunindo dados de diferentes hospitais. Os dados adquiridos foram então utilizados para prever a precisão de reconhecimento de padrões espirométricos.

Em diversas áreas da medicina podemos encontrar modelos matemáticos complexos, como o estudado em (NGUYEN-KY et al., 2012), que conseguiu mensurar a profundidade de drogas anestésicas, utilizando-se de sinais EEG e calculando valores através das transformadas de Fourier.

(ASHER, 2012), utiliza wavelets objetivando a classificação dos valores de dióxido de carbono presentes na corrente sanguínea, através do exame de capnografia, que possui um grande potencial em analisar indivíduos com doença pulmonar obstrutiva crônica ou indivíduos com restrição pulmonar.

No campo de caracterização de pacientes, como estudado em (MHETRE; Jitendra KHUBANI, 2012), o mesmo conseguiu estabelecer padrões de reconhecimento de valores baseandose nos valores do volume expiratório pulmonar dos pacientes.

Conforme (DEVI; VENKATESAN, 2013), o teste de espirometria é um teste essencial no caso de doenças respiratórias e doenças pulmonares relacionadas. Este trabalho trata da 
previsão de FEV1, que é um dos fatores mais importantes e um dos valores que decidem o diagnóstico sobre doenças respiratórias. Essa previsão de valores de FEV1 melhorou o método de diagnóstico da espirometria. Quando os dados são incompletos ou mal gravados, a precisão do diagnóstico das anomalias pode ser melhorada usando métodos baseados em SVM.

Considerando a área da pneumologia, verificamos que os pesquisadores estão desenvolvendo métodos numéricos avançados, como o estudado em (BETANCOURT et al., 2013), que utiliza de cálculos com wavelets no intuito de classificar o grau de severidade pulmonar em pacientes asmáticos.

Um trabalho realizado referente ao tema, de (LOPATA et al., 2013), demonstra os requisitos de espirômetros existentes no mercado e quais são as necessidades de leitura e aquisição dos dados necessários para realizar um exame aceitável e seu consequente correto diagnóstico, além de alertar para a necessidade de correção de uma parcela do exame conhecida como espaço morto.

O estudo de (LABATE et al., 2013) utiliza a decomposição de wavelets com o objetivo de retirar de sinais de ECG um sinal que expressa a respiração do indivíduo. Sua conclusão mostra que é importante a escolha correta da família de wavelets que irão ser utilizadas no estudo.

A clássica wavelet de Meyer tem boas propriedades. Possui derivação infinita, rápida atenuação e espectro finito. Os cálculos numéricos se beneficiam deste modelo, principalmente em grandes áreas da engenharia. No estudo de(ZHANG; DENG; HAN, 2013), é discutido as propriedades das wavelets de Meyer em sinais de imagens obtendo duas expressões centrais desenvolvendo um software para a aplicação de processamento de sinais.

Vimos em (VALENTINUZZI; JOHNSTON, 2014) a história da espirometria, onde apresenta diversos equipamentos que eram utilizados para analisar o comportamento fisiológico e dinâmico pulmonar, equipamentos que não possuíam na época qualquer cálculo matemático ou sistema digital de análise dos dados obtidos.

Também em (MYTHILI; SUJATHA, 2015), considera útil o uso de classificadores SVM para realizar o diagnóstico da espirometria, uma ferramenta valiosa no diagnóstico de patologias pulmonares, além de melhorar a precisão na caracterização de seu resultado. Foi utilizado um grande números de amostras correlacionando os valores encontrados dos exames e separandoos através do SVM.

(MAIA, 2015), avaliou em seu estudo da detecção da leishmaniose através de exames de espirometria, obtendo resultados satisfatórios em seu trabalho, atentando que as pessoas portadoras dessa patologia apresentaram comportamento semelhante a pessoas com restrição pulmonar nos exames, concluindo que a espirometria é uma ótima ferramenta para determinar patologias viscerais.

Em (KASSEM; HAMAD; EL MOUCARY, 2015) foi desenvolvido um modelo de equipamento com o intuito de registrar os valores de pico de fluxo expiratório (PFE) em portadores de asma. O equipamento comparava valores de fluxo pulmonar, correlacionando os valores li- 
dos com parâmetros aceitos na sociedade médica, dando um resultado instantâneo do paciente, que pode ser interpretado pelo médico que acompanha.

Conforme (MORETO TRINDADE; LINS FAGUNDES DE SOUSA; LUIS PEREIRA ALBUQUERQUE, 2015), "A espirometria é a principal ferramenta funcional respiratória e deve persistir por várias décadas." Este mesmo autor menciona que a morfologia das curvas devem constar do diagnóstico funcional, e o nosso trabalho apresenta resultados numéricos para auxiliar neste estudo morfológico e que podem ser num futuro utilizado para uma maior precisão do diagnóstico.

Conforme escrito em (LEE et al., 2016), parâmetros da espirometria convencionais têm demonstrado fraca correlação com os sintomas e estado de saúde de doença pulmonar obstrutiva crônica (DPOC). Embora seja bem conhecido que o padrão da curva de fluxo-volume expiratório (CVF) representa uma disfunção ventilatória, pequenas tentativas têm sido feitas para derivar os parâmetros quantitativos por meio da análise da curva. Neste estudo, o objetivo foi obter parâmetros úteis da capacidade vital forçada expiratória via análise gráfica e tentou validá-los em pacientes com DPOC, com sucesso.

Um estudo foi realizado em (SOLEIMANI et al., 2016) cujo objetivo foi realizar a medição de parâmetros de espirometria através da gravação de imagens do comportamento do tórax do indivíduo, conseguindo obter sete parâmetros necessários a avaliação pulmonar de forma satisfatória, próxima dos valores encontrados na espirometria.

Em (ULBRICHT, 2016), foi estudado o comparativo de previstos de forma a analisar as diferentes variações étnicas e concluiu que devido uma utilização errônea do previsto utilizado como parâmetro comparativo do exame, pode-se diagnosticar a pessoa incorretamente, ou seja, o mesmo indivíduo, dependendo do padrão de previsto utilizado, pode ser considerado como obstrutivo, restritivo ou normal. 


\section{FUNDAMENTAÇÃO TEÓRICA}

Neste capítulo iremos descrever o embasamento teórico que fundamenta nossa pesquisa, conforme as seções a seguir:

\subsection{FISIOLOGIA PULMONAR}

Podemos definir o sistema pulmonar de acordo com a seguintes estruturas: Brônquios, Bronquíolos, Alvéolos Pulmonares e Pulmões, incluindo a traqueia e a camada de revestimento que protege este sistema, a cavidade pleural.

\subsubsection{BRÔNQUIOS}

Os brônquios são ligações da traqueia até os pulmões, ramificando-se para formar a chamada árvore bronquial. Podemos dividi-los em três grupos: os principais, os lombares ou secundários (suprem os lobos pulmonares) e os segmentares ou terciários (suprem parte dos lobos) (TORTORA; DERRICKSON, 2017).

Os brônquios principais conectam a traqueia em direção ao pulmão através de um ponto de entrada conhecido como hilo. O diâmetro da traqueia é o dobro do diâmetro do brônquio principal. Contudo, o brônquio direito tem o diâmetro maior que o esquerdo e é menor em comprimento, possuindo metade do tamanho do direito e está alinhado mais diretamente com a traqueia do que o brônquio esquerdo. Isso se deve ao fato de o brônquio direito suprir o pulmão maior.Existe uma maior significância clínica pois o brônquio direito tem maior probabilidade de receber corpos estranhos do que o esquerdo (ZEMLIN, 2000), conforme a figura 1.

Figura 1 - Brônquios Pulmonares

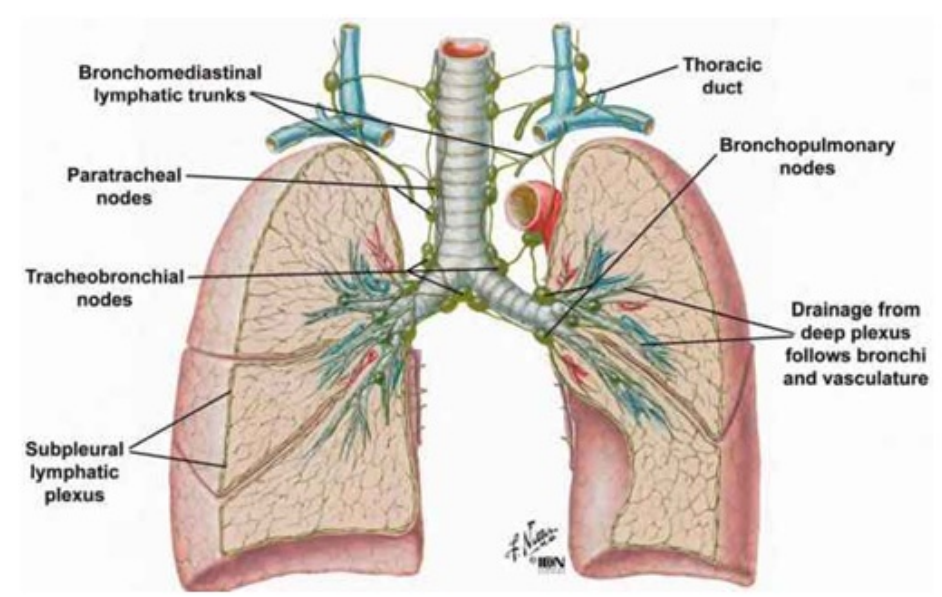

Fonte: NETTER, F. H. - Atlas de Anatomia Humana. 2ed. Porto Alegre: Artmed, 2000, acessado em 22/08/2016

Sua constituição se assemelha com a traqueia, ou seja, feitos de anéis cartilaginosos unidos por tecidos fibro elásticos (TORTORA; DERRICKSON, 2017). 
Contudo, possui em seu interior, revestindo-o, fibras de musculatura lisa mais completamente que a traqueia, além de possuir uma cobertura de epitélio, e suas paredes também conter um tecido elástico.

O brônquio direito divide-se em três brônquios lobares, sendo um para cada lobo do pulmão. Esses brônquios lobares também se dividem em brônquios chamados segmentares e cada um abastece um segmento do pulmão (TORTORA; DERRICKSON, 2017).

O brônquio esquerdo divide-se em dois brônquios lobares, que dele emergem oito brônquios segmentares, suprindo cada segmento do pulmão (ZEMLIN, 2000). a figura 2 demonstra essa estrutura.

Figura 2 - Brônquios Pulmonares em Destaque

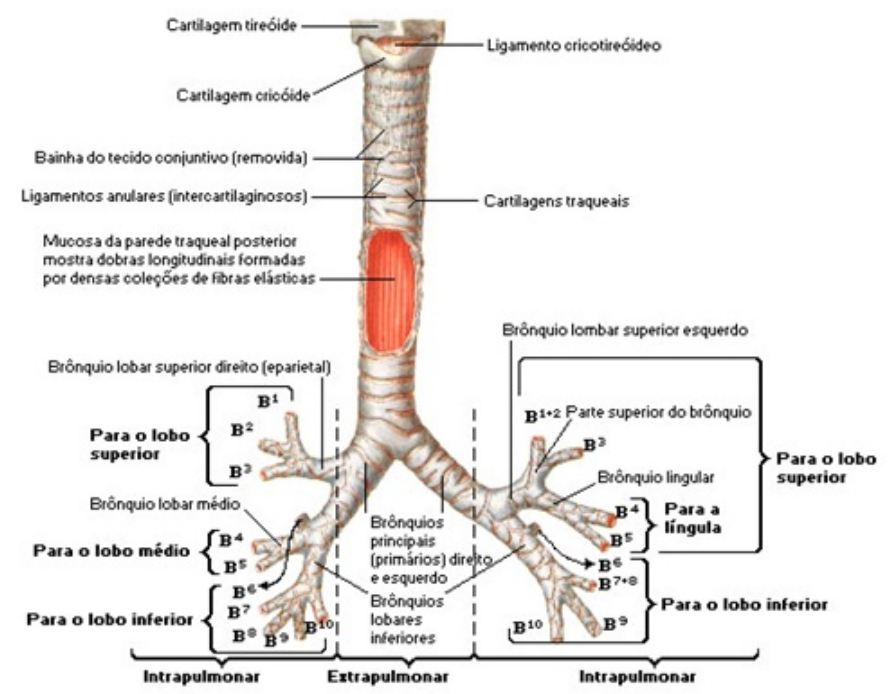

Fonte: NETTER, F. H. - Atlas de Anatomia Humana. 2ed. Porto Alegre: Artmed, 2000, acessado em 22/08/2016

\subsubsection{BRONQUÍOLOS}

São tubos de um milímetro ou menos de diâmetro. São considerados como resultado da divisões dos brônquios terciários, que vão se ramificando até ficarem cada vez menores. Um adulto possui cerca de vinte e quatro milhões de bronquíolos, constituindo a árvore bronquial (TORTORA; DERRICKSON, 2017).

Em sequência, devido as existirem repetidas divisões desses bronquíolos, dá-se origem aos bronquíolos terminais, comunicando diretamente aos dutos alveolares, se conectando em pequenos sáculos alveolares no interior do pulmão. Podemos notar que a grade cartilaginosa se torna menos presente ao passo que a musculatura bronquial aumenta nessa região (ZEMLIN, 2000), mostrado conforme a figura 3. 
Figura 3 - Bronquíolos Pulmonares em Destaque

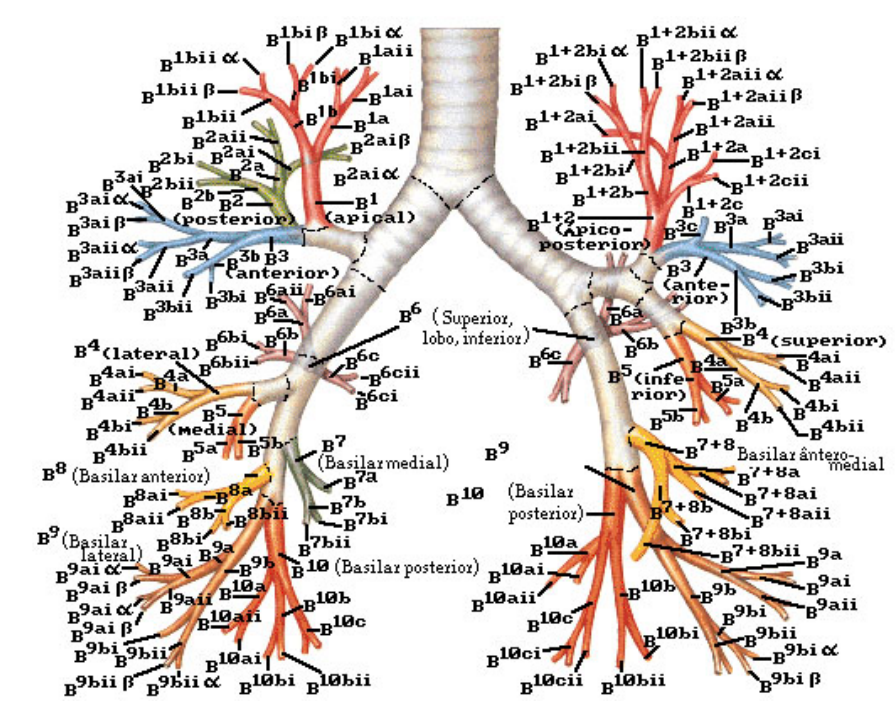

Fonte: NETTER, F. H. - Atlas de Anatomia Humana. 2ed. Porto Alegre: Artmed, 2000, acessado em 22/08/2016

\subsubsection{ALVÉOLOS}

Na parede dos bronquíolos terminais e por sua vez os sáculos alveolares, temos em torno de sete milhões de pequenas depressões conhecidas como alvéolos, constituindo aproximadamente trezentos milhões de alvéolos. Um alvéolo é denominado pela anatomia como qualquer depressão existente no corpo humano, logo, nos pulmões são chamados alvéolos pulmonares, mostradas na Figura 4.

Eles se situam sobre uma fina membrana, e revestidos por uma camada de células epiteliais. Suas paredes são revestidas por uma complexa rede de capilares, separados do ar alveolar através de uma barreira muito pequena (TORTORA; DERRICKSON, 2017).

Podemos dizer que dessa forma é possível construir uma rede de contato com o leito capilar de 70 a $90\left(\mathrm{~m}^{2}\right)$ metros quadrados, facilitando dessa maneira a troca gasosa entre oxigênio e dióxido de carbono.

No caso de uma oclusão de um duto alveolar, este revestimento possui algumas partículas, conhecida como fagócitos protetores, que são poros contidos nessa membrana e permitem uma certa passagem de ar lateralmente (ZEMLIN, 2000).

Este epitélio alveolar, o qual reveste os alvéolos é constituído por uma camada fina, perfazendo com que o núcleos celulares se tornem protusos por entre os espaços aéreos. Este tecido possui grande umidade, pelo fato de o epitélio ter propriedades secretoras. Como consequência disso, ocorre uma interface de ar e líquido entre o revestimento dos alvéolos. Assim o fenômeno de tensão superficial, devido a força de atração entre moléculas ocorre, e uma força é criada fazendo este revestimento líquido se comportar como um elástico, constantemente tentando se encurtar e resistir a uma força maior de estiramento. 
Figura 4 - Alvéolos Pulmonares

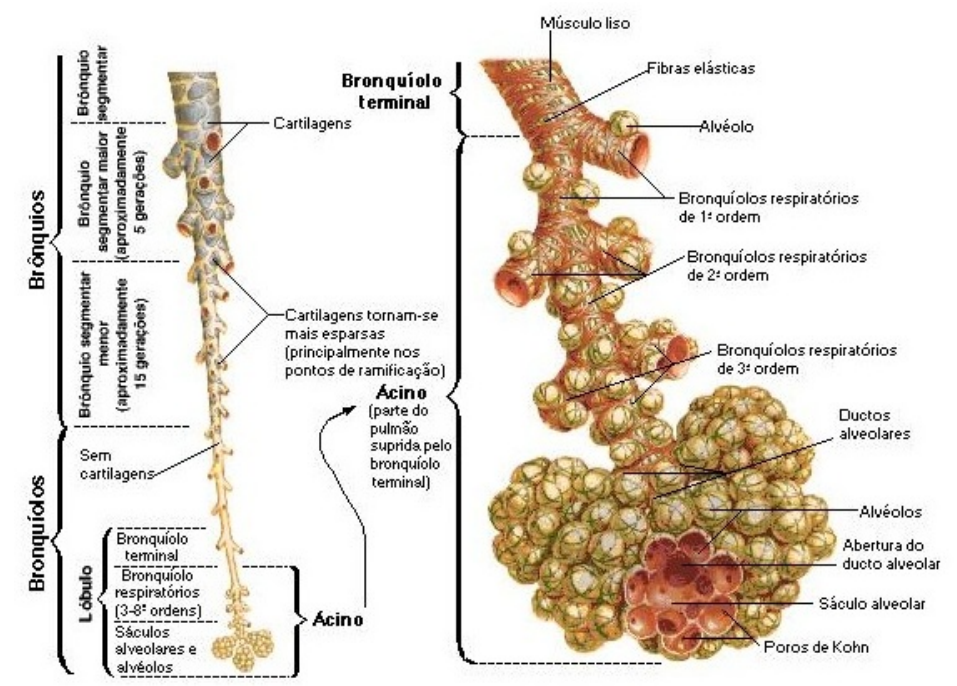

Fonte: http://ulbra-to.br/morfologia/2011/08/17/sistema-respiratorio, acessado em 22/08/2016

Esta tensão de superfície responde em dois terços pela elasticidade pulmonar, devido a tendência dos alvéolos sofrerem um colapso elástico e este colapso ser responsável pela elasticidade.

Assim, existem células conhecida com células alveolares, conhecidas como tipo dois (Tipo II), que secretam uma substância surfactante (um tensoativo pulmonar), e, misturando-se ao líquido molecular das superfícies alveolares, diminuem a tensão superficial em torno de cinco a dez vezes, fazendo com que o equilíbrio entre esses dois líquidos seja responsável também pela normalidade da função respiratória (ZEMLIN, 2000).

\subsubsection{PULMÕES}

Constituído por um tecido poroso e esponjoso, altamente elástico, com poucas fibras de musculatura lisa, em forma de cone, exemplificado na Figura 5. Essas duas estruturas são conhecida como pulmões, e seu tecido não é capaz de exercer algum tipo de força, apenas a fornecida pela sua elasticidade.

Em seu mediastino anterior existem alguns linfonodos mamários e vasos sanguíneos, no mediastino médio contém o coração, que é revestido por uma membrana chamada pericárdio. Em seu mediastino posterior localiza-se por trás o coração e o mediastino superior se localiza a traqueia e o esôfago, em conjunto com uma parte do sistema nervoso e irrigação sanguínea que suprem a cabeça (ZEMLIN, 2000).

Os pulmões adultos podem apresentar uma cor acinzentada ou placas negras, devido a inalação de poeira. Se posicionam de uma forma livre dentro das cavidades pleurais e são ligados ao corpo pelas raízes e ligamentos pulmonares. Essas raízes são denominadas pedículos e são constituídas pelas veias pulmonares, artérias e brônquios, e também pela irrigação sanguí- 
Figura 5 - Pulmão Vista Lateral

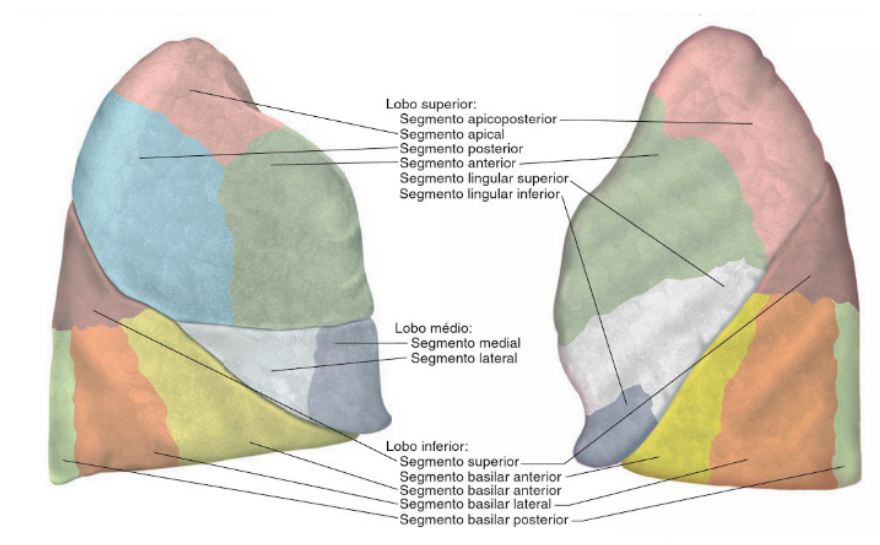

Fonte: Tank; Gest, 2009.

nea linfática e o complexo nervoso pulmonar, todas envolvidas por um tecido contribuindo com o mediastino.

Um ser humano possui dois pulmões, que diferem em forma, tamanho, capacidade pulmonar e peso. O pulmão direito é maior que o esquerdo, e também mais curto e largo, devido ao fígado ocupar parte da cavidade abdominal, forçando o arco lateral do diafragma. Entretanto, o coração ocupa mais espaço do lado esquerdo, diminuindo o tamanho do pulmão esquerdo.

Possui também cada pulmão um ápice e uma base, além das faces mediastinal e costal, incluindo também as margens posterior, anterior e inferior. Seu ápice é arrendondado e extendese pelos limites do tórax, chegando até a base do pescoço. Sua base é de grande tamanho, conformado com a anatomia do diafragma. O diafragma faz a separação da base do pulmão direito com o fígado, juntamente também do pulmão esquerdo com o fígado, baço e estômago (ZEMLIN, 2000). na figura 6 é mostrada uma outra vista dessa estrutura.

De acordo com suas fissuras, o pulmão direito se divide em três lobos: Lobos superior e inferior separados pelo lobo oblíquo e lobo médio separado pela fissura horizontal, ao passo que o pulmão esquerdo é dividido apenas em lobo inferior e superior, dividido pela fissura oblíqua mas não possui lobo médio por não possuir fissura horizontal (ZEMLIN, 2000). 
Figura 6 - Pulmão Vista Frontal

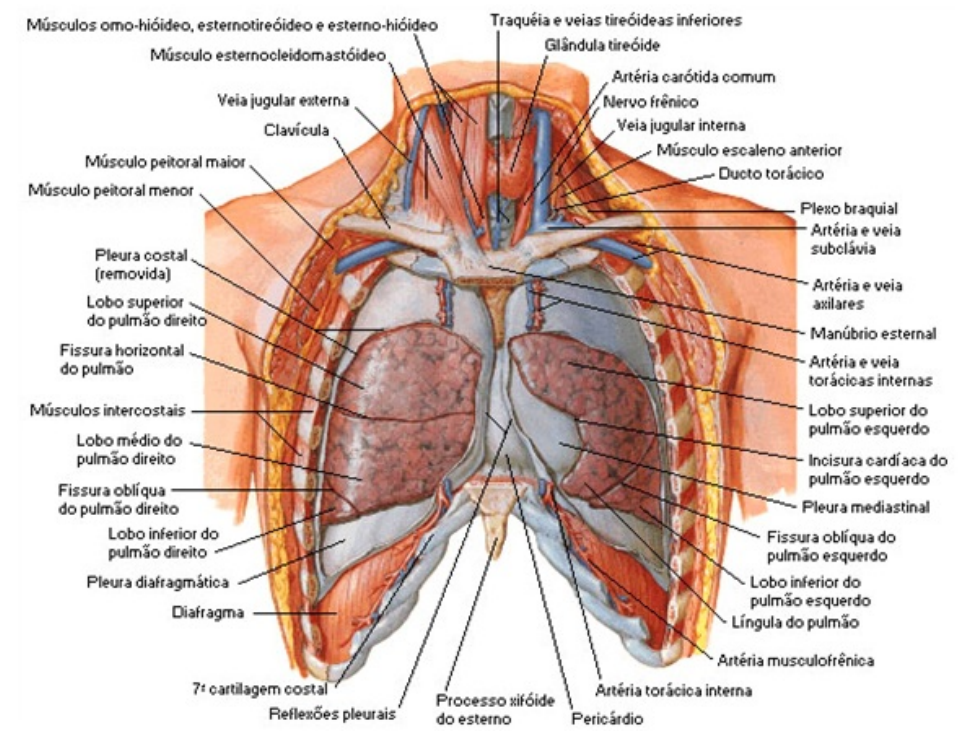

Fonte: NETTER, F. H. - Atlas de Anatomia Humana. 2ed. Porto Alegre: Artmed, 2000, acessado em 22/08/2016

\subsection{ESPIROMETRIA}

O exame de espirometria baseia-se na obtenção de valores de volume e fluxo de ar da respiração do paciente, e compará-los com resultados previamente conhecidos da população local, pois estes valores prévios mudam em função da localidade mundial. Este exame é realizado através de um método que converte o ar que circula pelos pulmões em um valor elétrico que possa ser lido por um sistema computadorizado, e através desse valor é possível calcular os parâmetros matemáticos construindo basicamente dois tipos de gráficos, como na Figura 7 , sendo o primeiro com eixos de leitura de Fluxo (L/s) em função do Volume (L), e o segundo com eixos de Volume (L) em função do Tempo (s) (C. A. PEREIRA, 2002). 
Figura 7 - Exame de espirometria

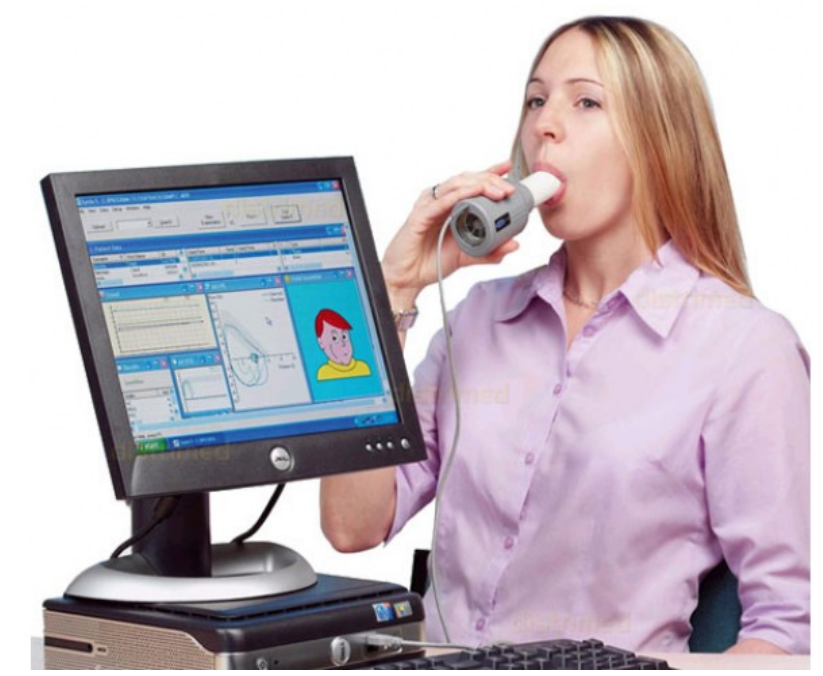

Fonte: http://www.theyellowpractice.co.uk/services/spirometry-lung-function-test/, acessado em 22/08/2016

Podemos classificar o resultado de um exame de espirometria basicamente em três tipos: normal, obstrutivo ou restritivo.

Os gráficos do exame de espirometria expressam basicamente duas características: $\mathrm{O}$ fluxo inspiratório, através da alça inspiratória no gráfico de fluxo em função do volume e o fluxo expiratório neste mesmo gráfico. Com o intuito de auxiliar o diagnóstico, é gerado um gráfico auxiliar que expressa todo o volume pulmonar em função do tempo (IRVIN; PH; MACINTYRE, 1995) e (RUPPEL; Paul L ENRIGHT, 2012).

Através dessas curvas, podemos interpretar alguns valores, considerados como básicos para a obtenção do resultado do exame de espirometria e necessários para a compreensão do exame. Estes valores são considerados como sendo os mínimos necessários para uma avaliação correta e um diagnóstico preciso do exame realizado, ou seja:

a) PEF: Pico de expiração forçado, ou o valor máximo em fluxo de ar que o paciente consegue expirar. É expresso em litros por segundo e seu valor é o ponto mais alto da alça expiratória.

b) FEF 25\%: É o valor chamado como fluxo expiratório forçado calculado após o término da manobra pois é ortogonal ao eixo de volume, ou o valor de fluxo em $25 \%$ do volume total.

c) FEF 50\%: É o valor chamado como fluxo expiratório forçado calculado após o término da manobra pois é ortogonal ao eixo de volume, ou o valor de fluxo em $50 \%$ do volume total.

d) FEF 75\%: É o valor chamado como fluxo expiratório forçado calculado após o término da manobra pois é ortogonal ao eixo de volume, ou o valor de fluxo em $75 \%$ do volume total. 
e) CVF: é o valor total do volume pulmonar expirado pelo paciente. Expressa a capacidade pulmonar do paciente, ou basicamente o tamanho do volume pulmonar do paciente desconsiderando o valor residual, que é o valor de volume necessário para não ocoro colabamentoagem pulmonar.

f) FIF 25\%: É o valor chamado como fluxo inspiratório forçado calculado após o término da manobra pois é ortogonal ao eixo de volume, ou o valor de fluxo em $25 \%$ do volume total.

g) FIF 50\%: É o valor chamado como fluxo inspiratório forçado calculado após o término da manobra pois é ortogonal ao eixo de volume, ou o valor de fluxo em $50 \%$ do volume total.

h) FIF 75\%: É o valor chamado como fluxo inspiratório forçado calculado após o término da manobra pois é ortogonal ao eixo de volume, ou o valor de fluxo em $75 \%$ do volume total.

Assim podemos descrever que o exame de espirometria, deve ser acompanhado, além do diagnóstico, pelos parâmetros obtidos juntamente com os gráficos de fluxo em função do volume e volume em função do tempo do paciente (C. A. PEREIRA, 2002).

Através da análise visual das curvas obtidas e da comparação de valores encontrados, podemos obter um diagnóstico do paciente, considerando-o como normal, obstrutivo e restritivo. De uma maneira superficial, as curvas para tais enfermidades podem ser expressas conforme a Figura 8:

Figura 8 - Formatos da Curva Fluxo x Volume

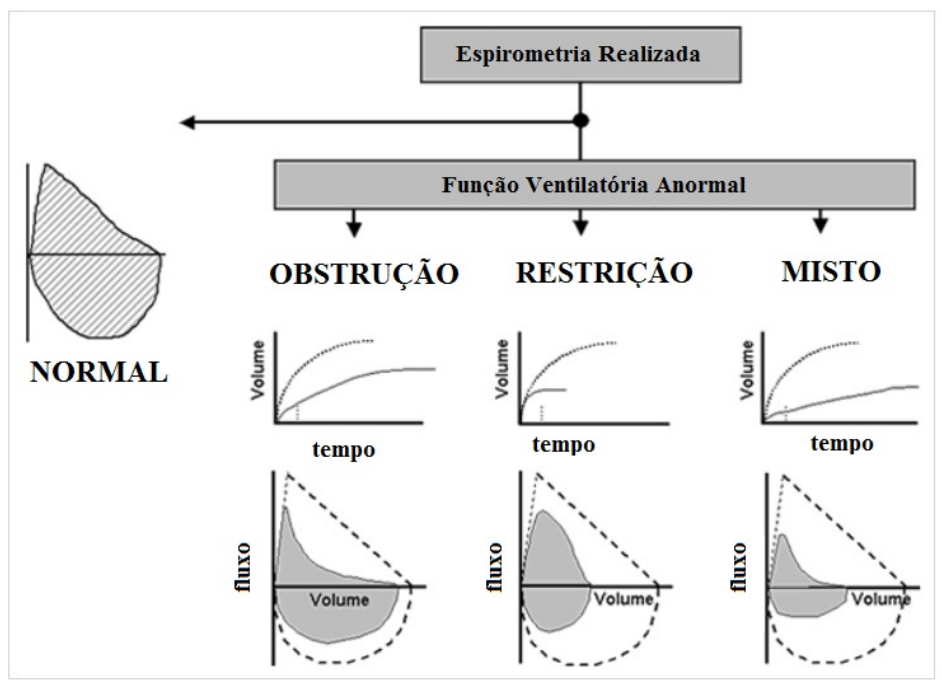

Fonte: Autor "adaptado de"Guldbrand, 2007. 
É possível visualizar na figura, que existem diferenças morfológicas nos valores máximos dos exames, mas que também a morfologia é alterada. É possível extrair valores do FEF (Fluxo Expiratório Forçado) mas não é possível mensurá-los em alguns casos, como o mostrado no capitulo de estudo de caso de nossa dissertação.

Podemos então padronizar o resultado de um exame de espirometria, através da análise visual em basicamente três tipos de diagnósticos: normal, restritivo e obstrutivo, sendo este último subclassificado em Obstrução das pequenas vias aéreas, Obstrução de Grandes vias, Obstrução Extratoráxica de grandes vias e Obstrução Crônica, esta última conhecida como DPOC, ou Doença Pulmonar Obstrutiva Crônica (GULDBRAND, 2007).

Assim, a DPOC tem se tornado conhecida, pois é diretamente ligada ao tabagismo e falta de exercícios físicos, e tem sido alvo de estudos nos últimos quinze anos, e ainda não se tem conhecimento de uma cura eficaz (RUPPEL; Paul L ENRIGHT, 2012).

A maioria dos equipamentos que realizam este tipo de exame são equipamentos importados, e apenas dois equipamentos possuem os valores de referência da população brasileira, conhecidos como preditos, sendo que os outros equipamentos se utilizam de valores comparativos internacionais.

Nos últimos quinze anos, houveram apenas dois estudos a fim de se obter os valores de referência da população brasileira, Esses dois estudos foram realizados pelo Prof. Dr. Carlos Alberto de Castro Pereira, sendo o mais atual deles C. A. Pereira (2002).

\subsection{MODELOS DE ESPIROMETROS}

Podemos dividir os espirômetros basicamente em dois tipos, que são conhecidos como espirômetro de fluxo e espirômetro de volume. Cada um possui sua particularidade, entre elas confiabilidade de resultados, visto que os espirômetros de fluxo possuem resolução de $50 \mathrm{ml}$ e os espirômetros de volume possuem resolução de $25 \mathrm{ml}$. Isso não quer dizer que um equipamento é melhor que outro, mas sim que os dois possuem resolução necessária para realizar um exame de espirometria com precisão (LEWIS, 1981).

\subsubsection{ESPIROMETROS DE FLUXO}

O espirômetro de fluxo é um equipamento que possui um sistema de leitura de valores de fluxo, através de um tubo com dimensões conhecidas, onde é analisado a diferença de pressão entre dois pontos que possuem uma pequena restrição do fluxo que passa por este tubo, permitindo assim uma pequena diferença de pressão que varia conforme os valores de fluxo variam dentro dessa tubulação. É conhecido como pneumotacógrafo, e geralmente realiza leituras de 0-12 (L/s) Litros por segundo (HANKINSON; GARDNER, 1982). 


\subsubsection{MIR ESPIROBANK}

É um espirômetro de fluxo, portátil, desenvolvido nos anos 1990. Como a figura 9 ilustra, possui uma pequena tela de cristal líquido onde é possível visualizar a realização do exame e uma impressora térmica que realiza a impressão do resultado.

Figura 9 - Espirômetro SpiroBank

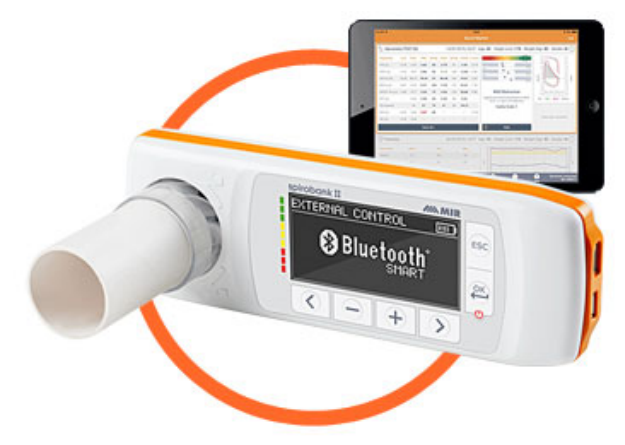

S

Fonte: http://www.spirometry.com/ENG/Products/spirobank2.asp, acessado em 22/08/2016

\subsubsection{SENSOR MEDICS M5000}

É um espirômetro de fluxo, mas apesar de ser portátil, é necessário o uso de um computador pessoal, e possui um módulo anexo para converter o fluxo de ar em sinal elétrico para o computador. Ou seja, tem a sua portabilidade comprometida, além de não possuir impressora dedicada, sendo necessário a impressão dos resultados posteriormente. A Figura 10 ilustra este equipamento.

Figura 10 - Espirômetro Sensor Medics

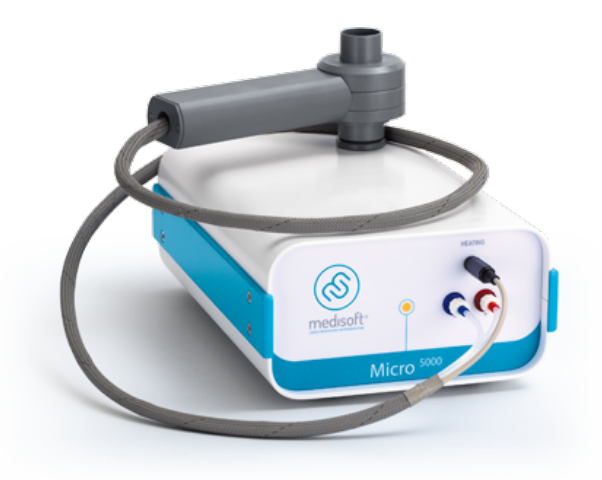

Fonte: http://www.medisoft.be/products/spirometry/micro-5000, acessado em 22/08/2016 


\subsubsection{EASY ONE}

É um espirômetro portátil, composto de uma pequena tela de cristal líquido no próprio equipamento, que permite uma rápida visualização do resultado, mas não em tempo real, comprometendo a precisão dos resultados. Depende da necessidade em transferir os dados do exame para um computador pessoal para realizar a impressão dos dados e laudos médicos. Podemos exemplificar este equipamento conforme a Figura 11.

Figura 11 - Espirômetro Easy One

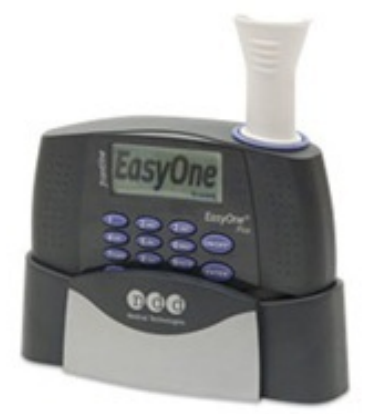

Fonte: http://www.nddmed.com/index/easyone-plus, acessado em 22/08/2016

\subsubsection{KOKO-PFT}

É um espirômetro de fluxo, mas que possui uma versatilidade maior, pois pode ser utilizado em um notebook e transmitir os resultados do exame por rede, wi-fi ou cabeada.

Tem sido um equipamento de referência nos últimos anos, e possui os valores previstos da normalidade brasileira, sendo o único no momento que possui essa funcionalidade.

Este foi o equipamento utilizado em nosso estudo e ilustrado como a Figura 12.

Figura 12 - Espirômetro Koko - PFT

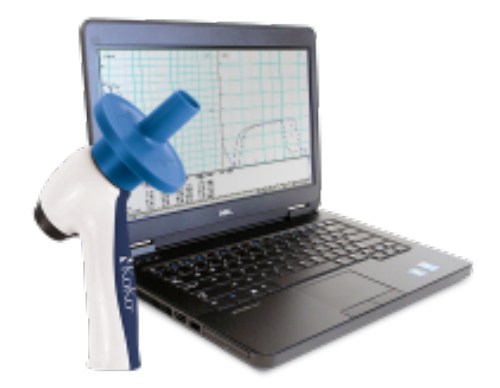

Fonte: http://www.nspirehealth.com/products/koko-testing-devices/, acessado em 22/08/2016 


\subsubsection{ESPIROMETROS DE VOLUME}

Um espirômetro de volume é um equipamento que realiza o exame de espirometria através da leitura de mudança de volume em um sistema fechado. Geralmente é utilizada uma campânula de doze litros de volume, e um sistema de detecção de movimento dessa campânula, que pode ser um potenciômetro linear ou um fuso mecânico motorizado. Não é portátil, geralmente é utilizado em grandes centros onde os pacientes realizam este tipo de exame, e são mais aceitos por permitir que o médico visualize o volume se alterando. A maior desvantagem é que pelo fato de ser um sistema fechado, selado ou por membrana ou por água, permite uma maior facilidade na contaminação dos pacientes, conhecida como contaminação cruzada, onde o uso do equipamento após ser utilizado por um paciente enfermo pode contaminar o paciente seguinte devido a secreções encontradas em seu interior (HANKINSON; GARDNER, 1982).

\subsubsection{SENSOR MEDICS HYPAIR}

Como ilustrado na Figura 13, é um equipamento que possui uma versatilidade muito grande, pois permite que sejam adicionados acessórios que ampliam a quantidade de exames. Também conhecido como laboratório de função pulmonar, realiza exames de pletismografia, que é um exame que analisa os volumes pulmonares do paciente, através da troca gasosa pulmonar em uma cabine fechada. Este tipo de exame é realizado com o intuito de conseguir medir o valor residual pulmonar, em pacientes que possuem alguma deficiência ou diminuição considerável da capacidade pulmonar total.

Figura 13 - Espirometro VMax2

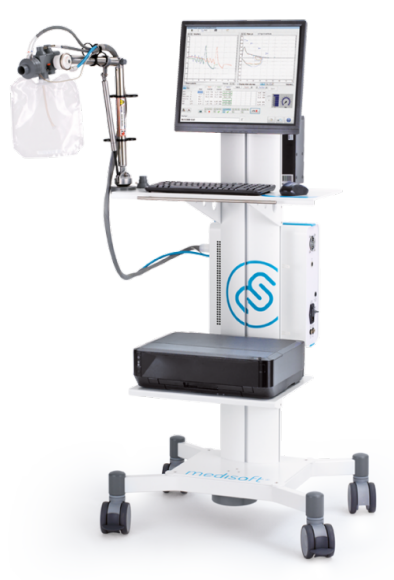

Fonte: http://www.medisoft.be/products/pft/hypair, acessado em 22/08/2016 


\subsubsection{ESPIROMETRO COLLINS CPL}

Trata-se de um equipamento que possui um espirômetro de volume e também um espirômetro de fluxo, mas sua grande vantagem é possuir um sistema analisador de diluição de hélio, além de um sistema eletrônico muito rápido para análise de volumes pulmonares, demonstrado na Figura 14. É um sistema mais complexo, não sendo alvo deste estudo, apenas para fins de conhecimento, possui também um módulo de análise de gases, permitindo exames de difusão pulmonar. Diferentemente do anterior explanado acima, já é integrado ao equipamento, não sendo necessário nenhum módulo adicional.

Figura 14 - Espirometro Collins CPL

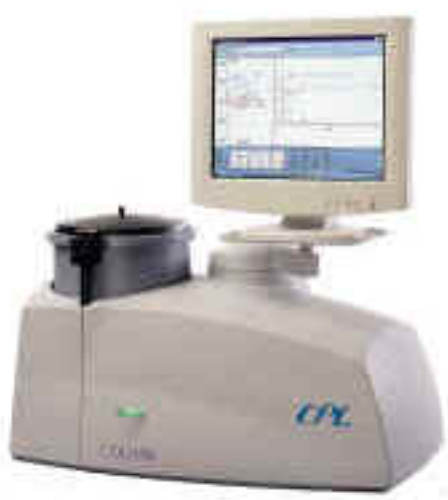

Fonte: http://www.bionetics.ca/BCCPL.htm, acessado em 22/08/2016 


\section{WAVELETS}

Conforme visto em Morettin (1999), a análise das wavelets já eram utilizadas por vários pesquisadores como uma alternativa a série de fourier clássica. As wavelets de J. S. Liénard e de X. Rodet se relacionam ao tratamento numérico de sinais sonoros e as de J. Morlet foram desenvolvidas para estocar e interpretar os sinais sísmicos, sendo que o físico A. Grossmann juntamente com Morlet foram os responsáveis pelo desenvolvimento da transformada das wavelets contínuas. O uso das wavelets aumentou a partir de 1985, quando foi dado um novo impulso a esta teoria através da contribuição matemática e especialistas em processamento de sinais.

Normalmente nos deparamos com sinais no ambiente, que podem ser interpretados como sinais elétricos. Por exemplo, uma pequena movimentação de terra em nosso planeta pode ser analisado através de sensores que captem essa movimentação, gerando um sinal elétrico que pode ser interpretado e gerado um gráfico, conhecido como sinal sísmico. Um sinal mio-elétrico comum é o estudo das ondas cerebrais, que são sinais de baixa amplitude e devem ser lidos, posteriormente filtrados a fim de se obter alguma característica que possa analisar este sinal; esses sinais são conhecidos como EEG, ou eletro-encefalografia (SMITH, 2005) e (CHEN; LIANG; HO, 2012).

A transformada wavelet vem sendo utilizada como uma ferramenta alternativa para processamentos digitais de imagens e de sinais, pelo fato de gerar matrizes esparsas, sem comprometer a qualidade de resultado final, além de possibilitar o ajuste no domínio da frequência, amplitude e tempo. Tem sido utilizada nos mais diversos campos que não possuem uma solução no campo de valores reais, possibilitando um acréscimo no campo de pesquisa onde a rapidez computacional é requerida (BELARDI; FAUSTO, 2013).

Podemos definir uma transformada da wavelet mãe a partir da seguinte equação:

$$
\psi_{a, b}(x)=|a|^{-1 / 2} \psi\left(\frac{x-b}{a}\right), a, b \in R, a \neq 0
$$

Os parâmetros a e b variam continuamente, denominando-se wavelets e definidos como se segue:

$$
\psi_{j, k}^{(H)}(x)=2^{j / 2} \psi\left(2^{j} x-k\right) j, k \in Z
$$

As wavelets de Haar são definidas no seguinte intervalo, sendo $\varphi$ a wavelet pai:

$$
\varphi^{(H)}(x)= \begin{cases}1 & 0 \leq x<0.5, \quad e \\ 0 & \text { ParaOutros Intervalos }\end{cases}
$$

Assim então, podemos nos basear que as wavelets conforme estudado por Haar (MEYER, 1993), que descreveu as wavelets como uma base ortonormal definida em um domínio [0,1], e que pode ser expressa graficamente conforme a figura 15 : 
Figura 15 - Wavelet de HAAR
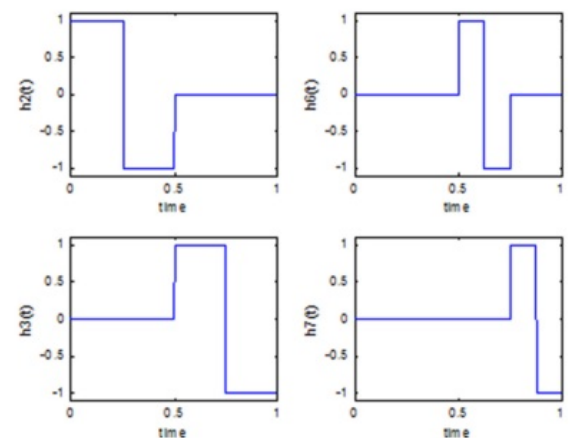

Fonte: Chen; Liang; Ho, 2012.

Além de Haar temos outros tipos de wavelets tais como Battle-Lemarié, Chapéu Mexicano e Shannon como visto em Belardi e Fausto (2013), além de meyer podendo ser vista em Zhang, Deng e Han (2013).

Representamos as Wavelets de Meyer, conforme a seguinte figura 16:

Figura 16 - Wavelet de Meyer

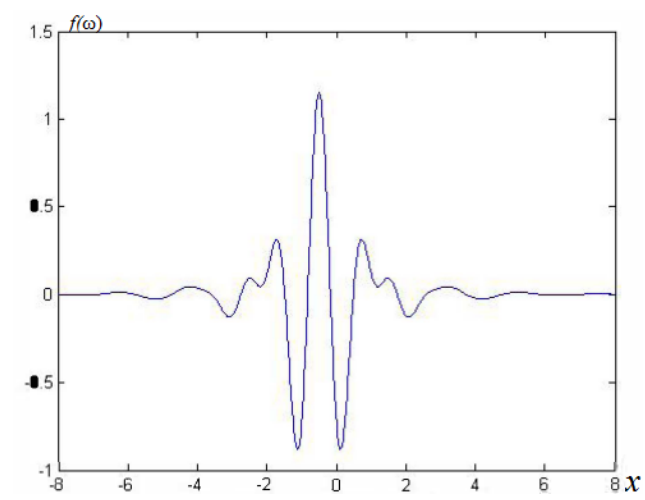

Fonte: Zhang; Deng; Han, 2013.

Esta wavelet pode ser definida pelas seguintes funções:

$$
\begin{gathered}
f(\omega)=\left\{\begin{array}{c}
0, \quad \omega \leq 0 \\
e^{-1 / \omega^{2}}, \quad \omega<0
\end{array}\right. \\
h(\omega)=\frac{f\left(\frac{4 \pi}{3}-\omega\right)}{f\left(\omega-\frac{2 \pi}{3}\right)+f\left(\frac{4 \pi}{3}-\omega\right)} \\
\phi(\omega)=\sqrt{h(\omega) h(-\omega) \hat{\psi}(\omega)} \\
e^{-i \omega / 2}=\sqrt{\phi(\omega / 2)^{2}-\phi(\omega)^{2}}
\end{gathered}
$$


Na Figura 17 a seguir representamos a Wavelet de Battle-Lemarié, formulada por :

$$
\varphi(x)=\left\{\begin{array}{c}
\frac{1}{2} x^{2}, \quad 0 \leq x<1 \\
-x^{2}+3 x-\frac{3}{2}, \quad 1 \leq x<2 \\
\frac{1}{2}(x-3)^{2}, \quad 2 \leq x<3
\end{array}\right.
$$

Figura 17 - Wavelet de Battle-Lemarié

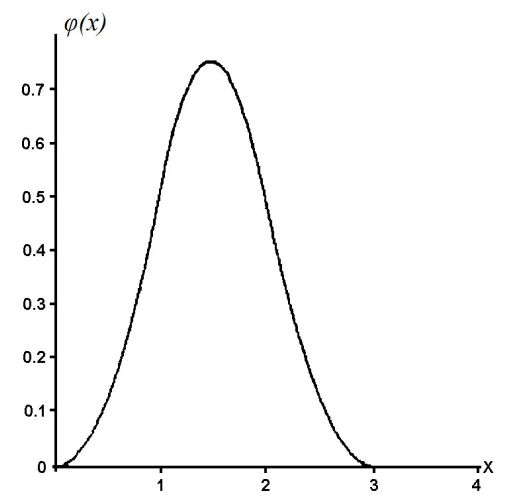

Fonte: Belardi; Fausto, 2013.

Na Figura 18 representamos a wavelet Chapéu Mexicano, que é formulada por:

$$
\psi(x)=\left(1-x^{2}\right) e^{-x^{2} / 2}
$$

Figura 18 - Wavelet Chapéu Mexicano

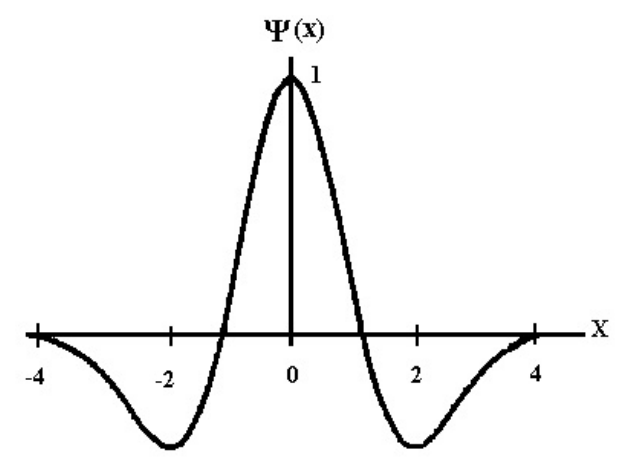

Fonte: Belardi; Fausto, 2013. 
A Wavelet de Shannon é definida pela seguinte equação:

$$
\psi(x)=\frac{\sin \left(\frac{\pi(x)}{2}\right)}{\frac{\pi x}{2}} \cos \left(\frac{3 \pi x}{2}\right)
$$

Esta wavelet pode ser demonstrada pela Figura 19.

Figura 19 - Wavelet de Shannon

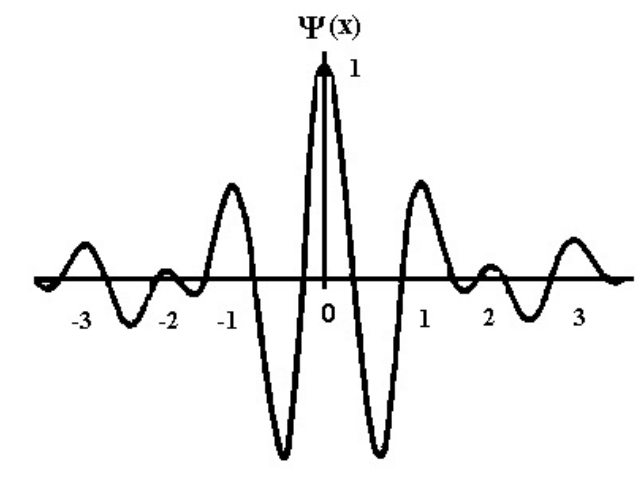

Fonte: (BELARDI; FAUSTO, 2013). 


\section{METODOLOGIA}

Na metodologia que utilizamos para obtenção dos valores a serem analisados foi utilizado um espirômetro modelo KOKO PFT (Koko®, tipo PFT, nSpire Health Inc., CO, EUA), e, através do software versão 4.15 realizarmos a extração dos dados das curvas espirométricas.

Assim, o software de aquisição de valores é mostrado como na Figura 20, sendo esta a tela principal do software.

Figura 20 - Inicio da Extração dos valores

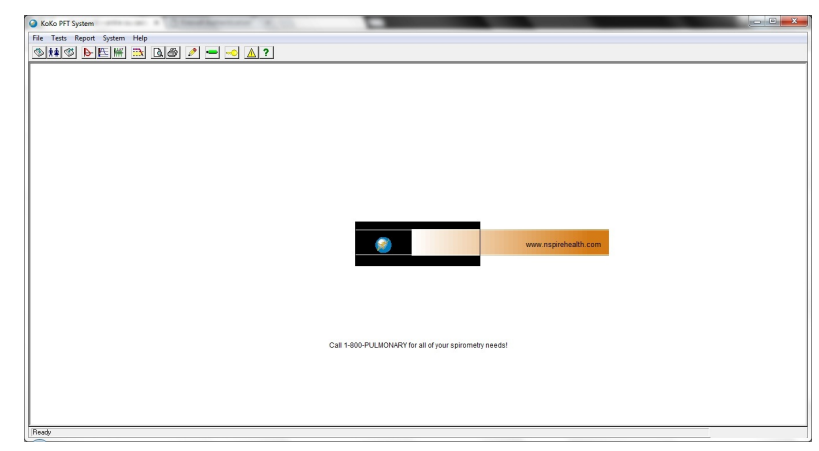

Fonte: Autor.

Para replicação da simulação executada, deve-se clicar com o mouse em "FILE", o qual irá abrir um pequeno menu, e selecionarmos a opção "Import/export"e em seguida clicarmos na opção "Export FVC test (ATS/ERS2005)". Neste momento abrirá uma janela e então, o software solicitará para selecionar qual cadastro de exame realizado para que seja exportado, conforme Figura 21:

Figura 21 - Extração dos valores

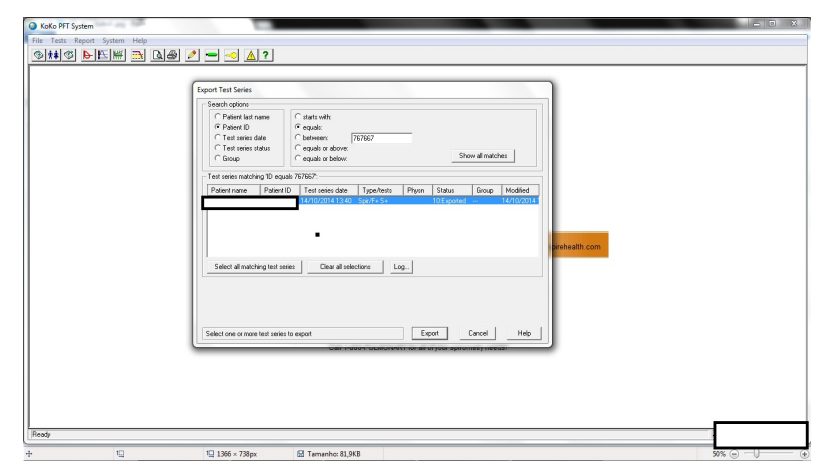

Fonte: Autor. 
Então, após este passo selecionamos a opção export, onde em seguida será mostrado na tela a seguinte imagem conforme a Figura 22:

Figura 22 - Exportação dos valores

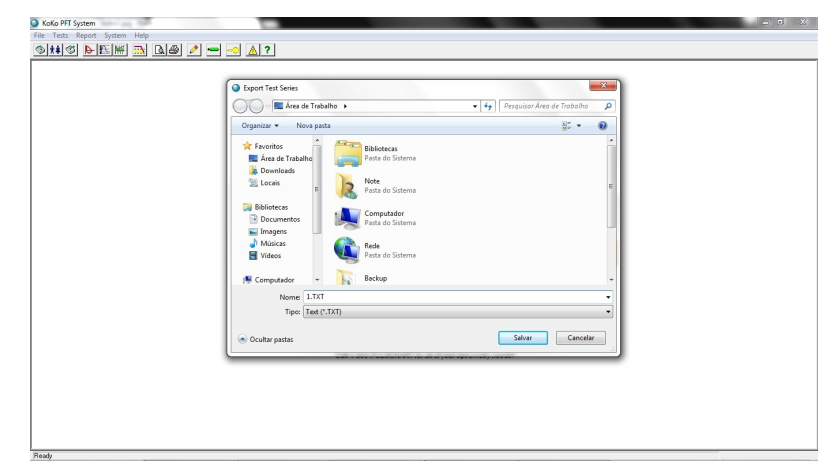

Fonte: Autor.

Após a execução destes passos, o usuário deve escolher um local onde será armazenado o arquivo que contém os dados exportados. Nota-se que se trata de um arquivo em formato texto com extensão ".TXT"que possui os dados do exame de forma numérica. De todos os modos de exportação que este software possui, este é o mais correto pois os outros modos, são para exportação em formato que possam ser lidos por sistemas de software que gerenciam clinicas médicas.

Assim, realizamos a análise dos dados exportados e encontrados neste arquivo valores numéricos, que serão objeto deste estudo, e serão inseridos no Matlab conforme a metodologia explanada a seguir e também pelos resultados obtidos.

Para tanto, após abrir o Matlab, pode-se clicar em "New script"e inserir o código necessário para realizar a leitura dos dados. Em seguida basta executá-lo para que o Matlab importe os dados do Excel e exiba o gráfico do sinal. Este gráfico confirma que os dados foram importados corretamente.

Podemos verificar que o valores estão inseridos corretamente comparando os gráficos da forma de onda do sinal no Excel e no Matlab. Estes gráficos devem ser iguais.

A determinação dos coeficientes de wavelets parte do ponto onde, com os dados do sinal importados para dentro do Matlab são: a entrada dos dados no Toolbox de wavelets, a determinação dos coeficientes das wavelets, a exportação destas informações para o Excel e ao final a análise estatística do sinal ainda no Toolbox.

Assim, de acordo com a metodologia apresentada, passamos a inserir os dados de um paciente, que será a base para nossa replicação em outros pacientes.

Em seguida aplicamos o algoritmo que se encontra no Apêndice B, onde conseguimos inserir os dados no Matlab, conforme Figura 23 : 
Figura 23 - Importação do Dados no Matlab

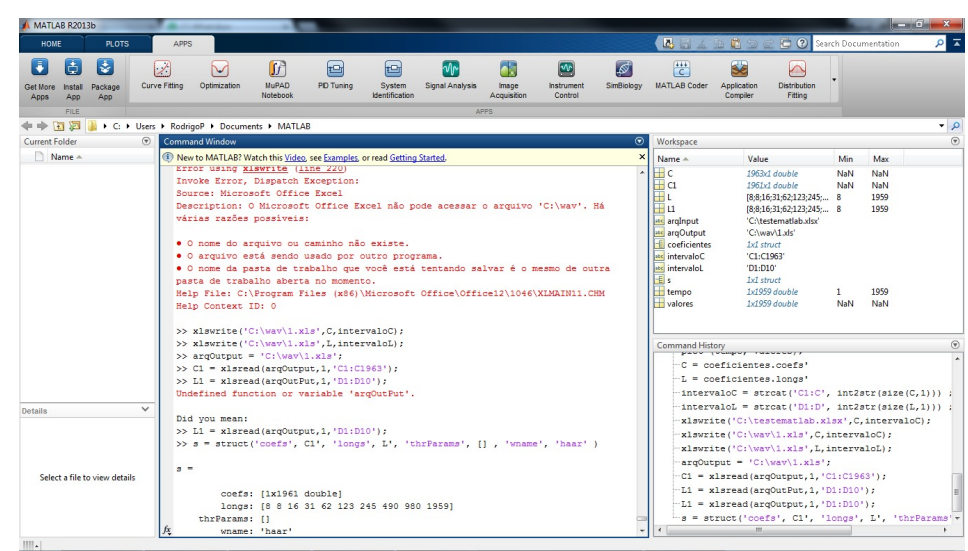

Fonte: Autor.

Validamos a importação dos resultados, aplicando a leitura do gráfico e exibindo os dados em tela gráfica, dentro do ambiente do aplicativo do Matlab, conforme a Figura 24 :

Figura 24 - Importação do Dados

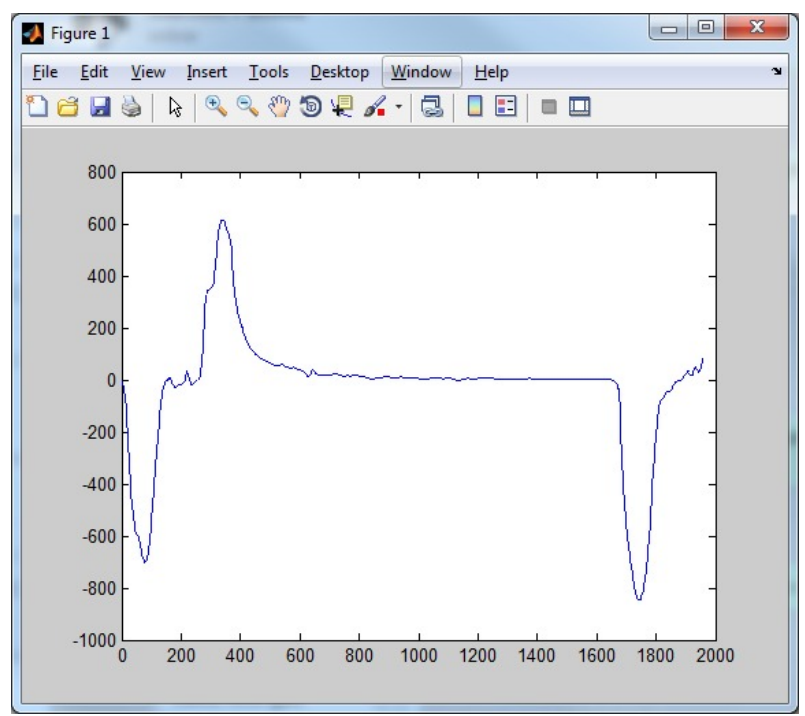

Fonte: Autor.

Em seguida, utilizamos o toolbox das wavelets do aplicativo do Matlab, onde obtivemos os gráficos em nível de resolução 3 e 5, conforme a Figuras 25 e 26. 
Figura 25 - Coeficientes de Detalhes

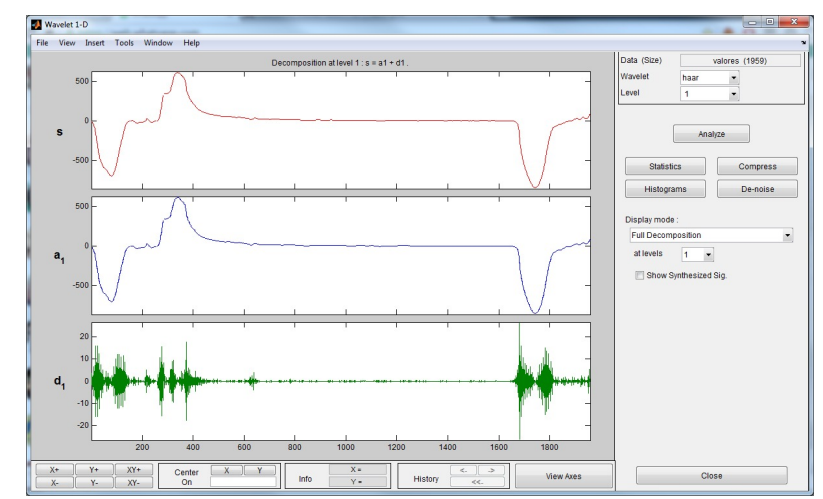

Fonte: Autor.

Figura 26 - Importação do Dados no Matlab

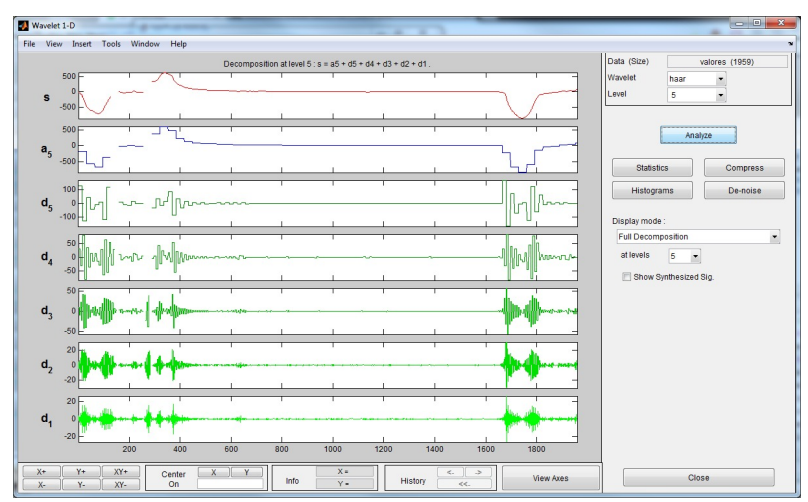

Fonte: Autor.

A amostras utilizadas foram pré classificadas em masculino e feminino e também separadas em amostras normal, obstrutiva e restritiva.

A análise foi feita nas seguintes etapas: extração dos Dados, uso do toolbox do aplicativo do MatLab e análise dos resultados.

Utilizando o algoritmo proposto, existe a possibilidade de selecionar o tipo de wavelet apenas mudando a variável "type".

Para validação dos resultados, utilizamos as wavelets de Haar, Meyer, Daubechie e Symlets a fim de verificarmos qual delas responderia melhor para caracterização das curvas espirométricas. 


\section{RESULTADOS OBTIDOS}

Os Resultados que obtivemos foram suficientemente satisfatórios em possibilitar um biomarcador auxiliar na análise de exames de espirometria, podendo auxiliar na elaboração de um laudo médico mais confiável. A seguir mostramos como foram utilizados os dados coletados e como foram obtidos os seus resultados numéricos para classificação de seus resultados.

\subsection{DADOS UTILIZADOS}

Foram utilizados um conjunto de amostras de 60 exames, sendo 20 exames de indivíduos normais, 20 exames de indivíduos obstrutivos e 20 exames de indivíduos restritivos. Cada uma das amostras de 20 exames foram divididas em 10 indivíduos do sexo masculino e 10 indivíduos do sexo feminino.

As figuras 27 e 28 apresentam as diferenças dos valores CVF e FEV1 considerando os indivíduos com as mesmas características físicas porém alterando-se somente os sexos.

Figura 27 - Previsto da Persona Sexo Masculino

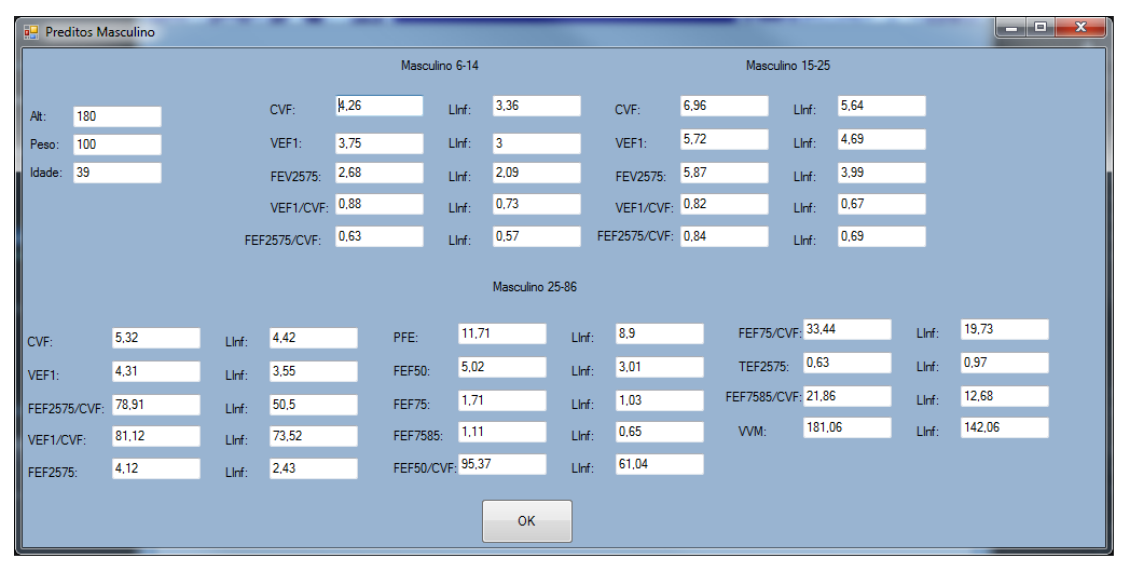

Fonte: Autor. 
Figura 28 - Previsto da Persona Sexo Feminino

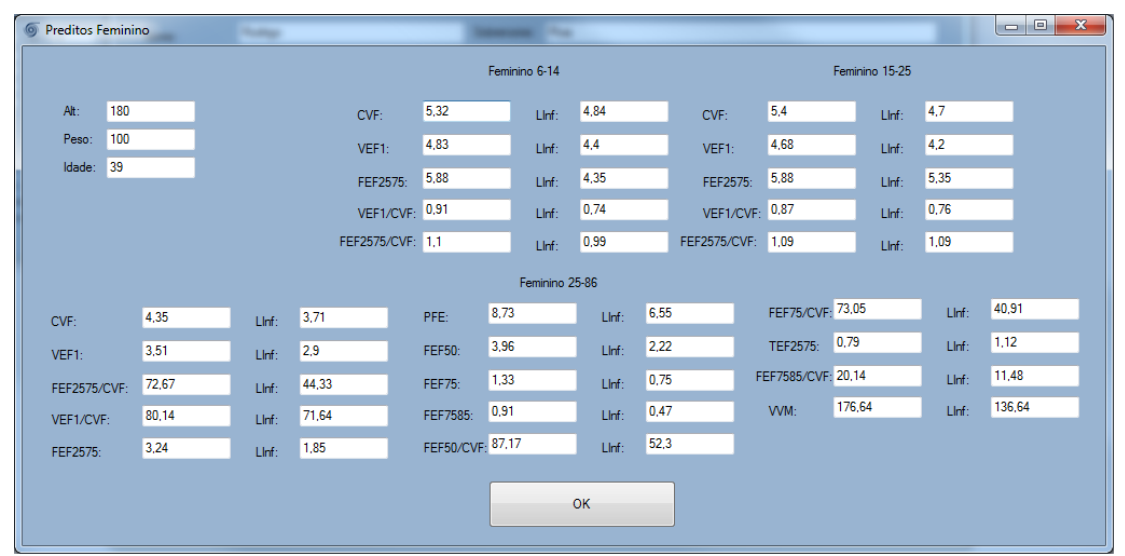

Fonte: Autor.

As alterações observadas em relação aos valores de CVF e FEV1, de acordo com as diretrizes da sociedade brasileira de pneumologia, são consideradas aceitáveis pois se encontra em um valor inferior a dez por cento como visto em (C. A. C. PEREIRA, 1996).

Desta forma os testes da metodologia foram feitos utilizando os dados de ambos os sexos.

Utilizando os valores numéricos dos exames fornecidos pelo equipamento, que são os valores lidos pelo equipamento em fluxo por segundo em função do tempo, as Figuras 29, 30 e 31 mostram as curvas do comportamento dos pacientes diagnosticados como normal, obstrutivo e restritivo respectivamente, com as séries de 20 exames cada.

Figura 29 - Curvas dos Pacientes Normais

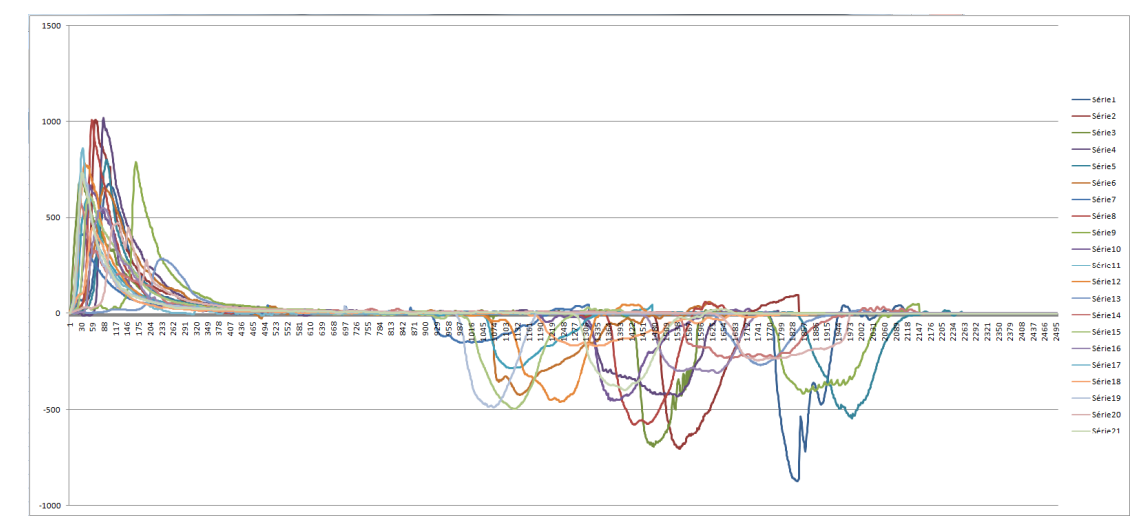

Fonte: Autor.

A figura 32 apresenta a covariância dos pacientes versus os números de amostras antes da aplicação da wavelets pelo aplicativo matlab de nossa metodologia.

Assim, podemos perceber que não é possível distinguir os valores numéricos de covariância obtidos antes da aplicação das wavelets, não sendo possível caracterizar os pacientes como normais, obstrutivos e restritivos. Para se obter os valores de covariância do gráfico da figura 32 , foi utilizado os valores que estão apresentados na tabela 1 , provenientes da exportação do exame: 
Figura 30 - Curvas dos Pacientes Obstrutivos

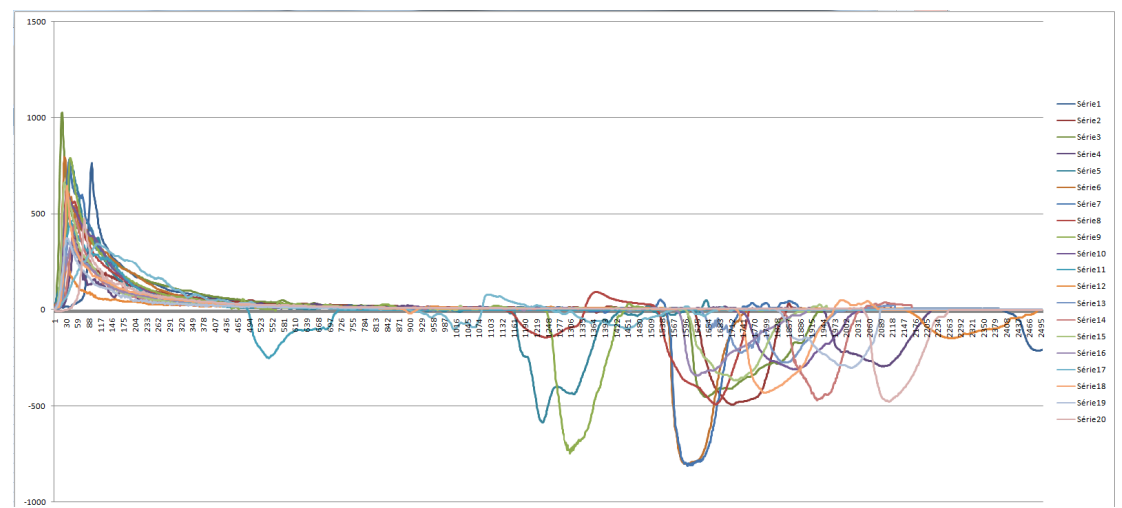

Fonte: Autor.

Figura 31 - Curvas dos Pacientes Restritivos

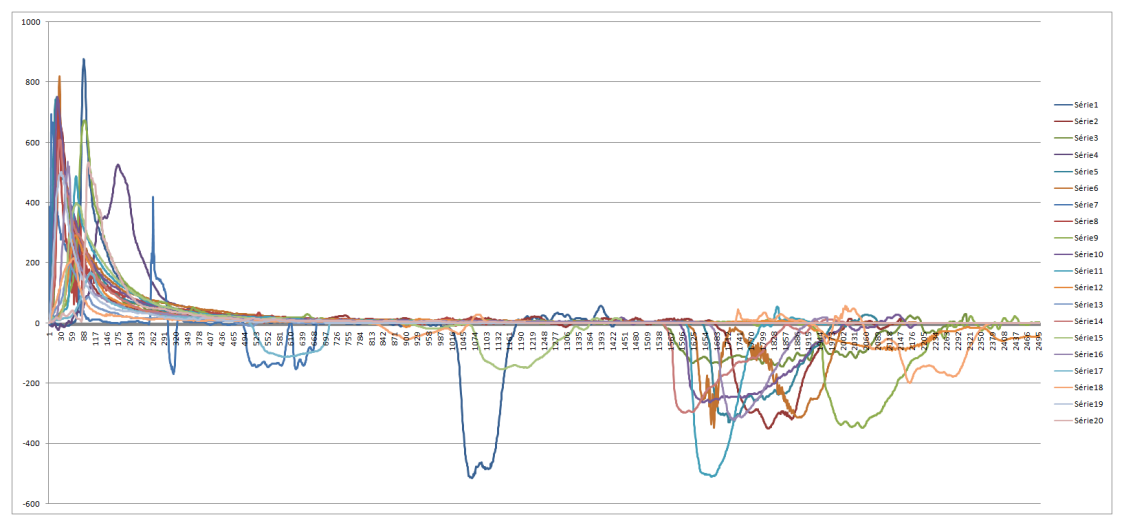

Fonte: Autor.

Figura 32 - Curvas dos Pacientes Conforme Covariância

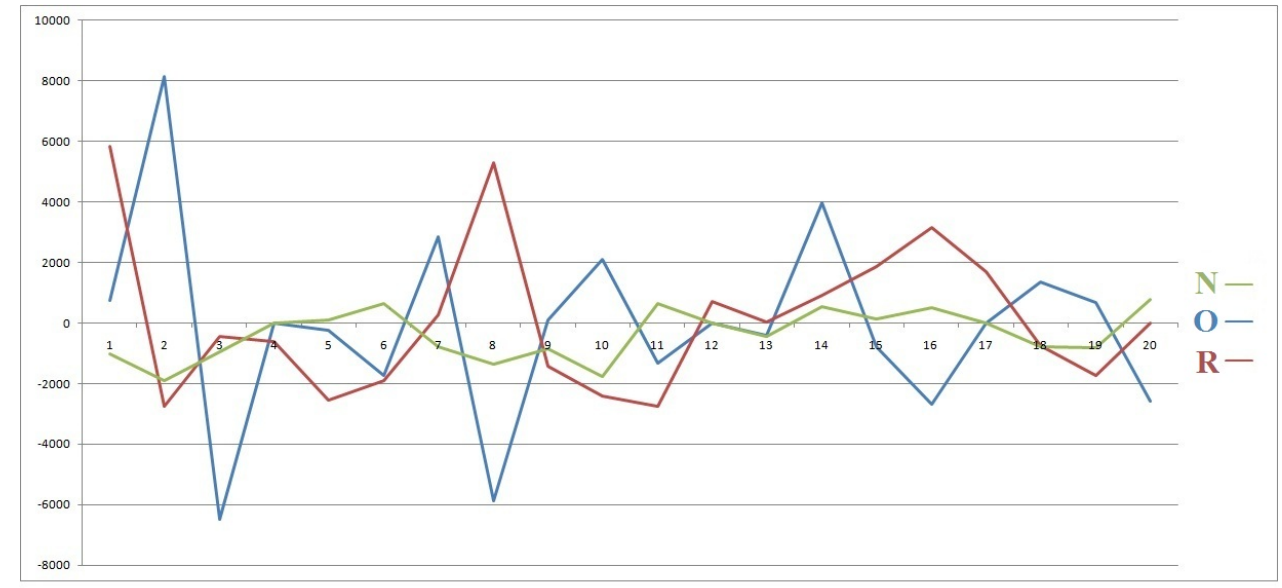

Fonte: Autor. 
Desejamos salientar que entre as wavelets aplicadas, ou seja, Haar, Chapéu Mexicano, etc, através do toolbox do aplicativo do matlab, a que obtivemos melhor eficiência para representar os curvas de pacientes normais, obstrutivos e restritivos foi a Wavelet de Meyer.

A tabela 2, apresenta os valores dos coeficientes calculados em 8 indivíduos do sexo masculino de diagnóstico normal, após a aplicação das wavelets de Meyer. São mostrados os valores de 1-10, período de expiração forçada, valores de 800 a 820 com contexto do final da manobra de expiração forçada e os valores de 1540 a 1550 que são os valores durante a inspiração voluntária de uma amostra de 2550 pontos. 


\subsection{AVALIAÇÃO DA APLICAÇÃO DE WAVELETS}

Com a metodologia adotada, observamos que existe uma diferença numérica visual entre os pacientes considerados normais, obstrutivos e restritivos com a aplicação das wavelets.

As figuras 33, 34 e 35, aplicando-se as wavelets de Meyer, que foi a que apresentou a maior discrepância do sinal estudado frente as outras wavelets, considerando as amostras $\mathrm{C} 1, \mathrm{C} 25$ e C42 que foram escolhidas aleatoriamente entre os dados obtidos para exemplificar a variação do sinal resultante na aplicação das wavelets, corresponde a um indivíduo do sexo masculino sendo normal, obstrutivo e restritivo respectivamente.

Figura 33 - Coeficientes dos dados de C1

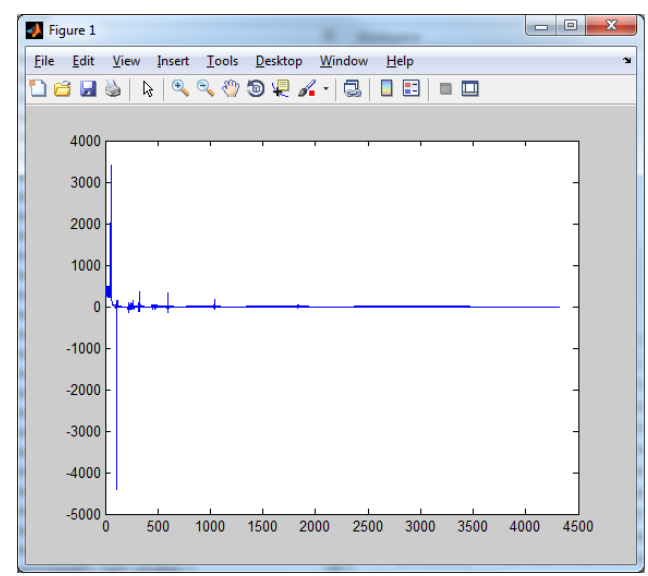

Fonte: Autor.

Figura 34 - Coeficientes dos dados de C25

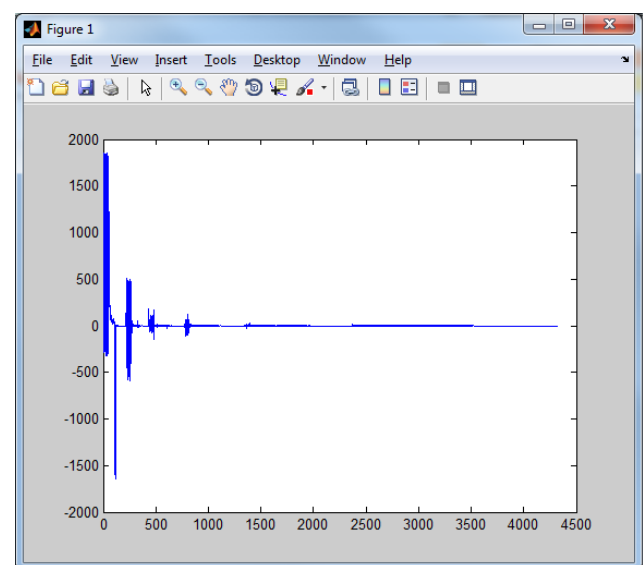

Fonte: Autor. 
Figura 35 - Coeficientes dos dados de C42

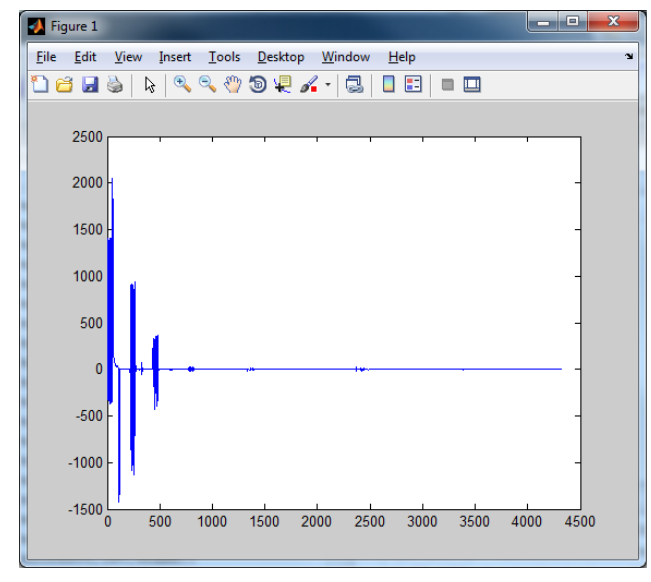

Fonte: Autor.

As figuras 36 e 37 apresentam os resultados obtidos com a aplicação das wavelets de Meyer, para o sexo masculino e o sexo feminino respectivamente. Os eixos das figuras são a amplitude dos coeficientes versus o numero de pacientes.

Figura 36 - Covariancia Sexo Masculino

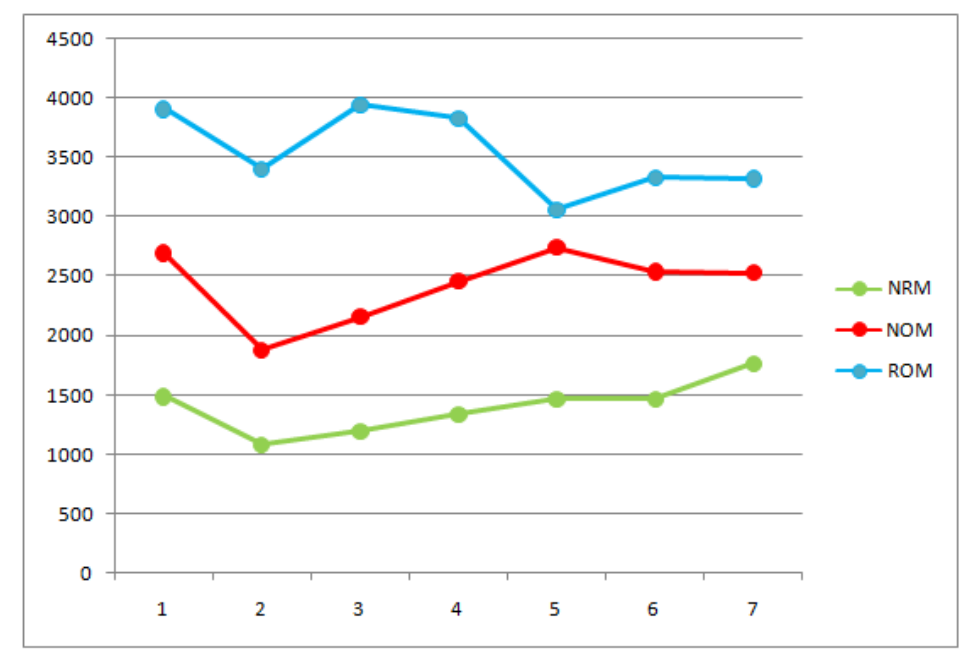

Fonte: Autor. 
Figura 37 - Covariancia Sexo Feminino

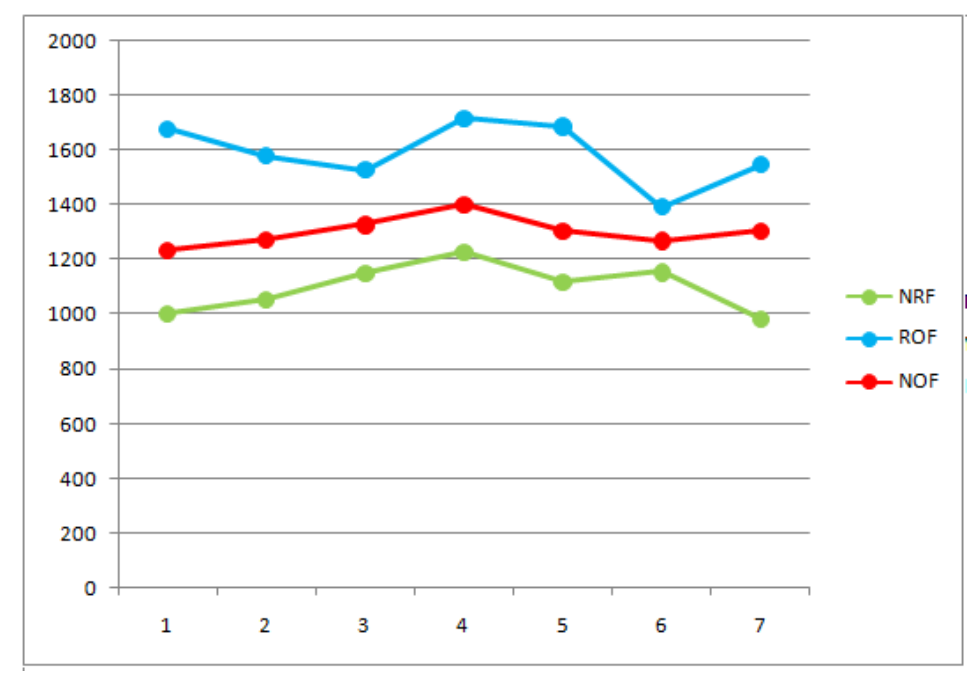

Fonte: Autor.

Podemos observar que com a análise da covariância após a aplicação das wavelets pelo aplicativo matlab, podemos constatar de forma visual e numérica, que existe uma diferença significativa e possuindo a mesma acurácia ${ }^{1}$ entre os valores normais (NRM e NRF, sendo NRM normal masculino e NRF normal feminino) obstrutivos (NOM e NOF, sendo NOM obstrutivo masculino e NOF obstrutivo feminino) e restritivos (NRM e NRF, sendo NRM restritivo masculino e NRF restritivo feminino) para ambos os sexos.

Assim, através da análise dos dados utilizados para construir as figuras 36 e 37, ou seja, considerando-se os valores de covariância, realizamos uma classificação em faixas, tanto para o sexo masculino quanto o sexo feminino, sendo possível determinar a variação de um paciente normal, obstrutivo e restritivo, incluindo dentro de cada diagnóstico uma faixa de máximo e mínimo, certificando com maior precisão ${ }^{2}$ a análise do resultado.

\footnotetext{
${ }^{1}$ Acurácia significa o resultado do valor medido ser a real grandeza que deve ser mensurada. (C. A. C. PEREIRA, 1996)

${ }^{2}$ Precisão significa a medição da confiabilidade do instrumento. (C. A. C. PEREIRA, 1996)
} 
A tabela 3 apresenta os valores de covariância para o sexo masculino e feminino, ou seja, os valores encontrados cujos valores máximos e mínimos representam a faixa de onde o diagnóstico do exame pode ser encontrado com nossa metodologia:

Desta forma, podemos concluir que por exemplo, o padrão restritivo do sexo masculino apresenta valores de covariância finais da analise acima de 3062,28, os valores obstrutivos apresentam valores entre 1876,54 - 2739,91 e os valores normais apresentam valores entre 1079,38 - 1765,94.

Por sua vez, os valores femininos apresentam valores de covariância acima de 1392,23 para restrição pulmonar, obstrutivos valores entre 1235,20 - 1402,54 e normais com valores de 984,70 - 1228,11.

Para validarmos a metodologia escolhemos aleatoriamente o exame de 12 pacientes, 6 do sexo masculino e 6 do sexo feminino, com o diagnóstico de normal, obstrutivo e restritivo. Os resultados obtidos estão descritos na 4.

\subsection{DISCUSSÕES SOBRE A METODOLOGIA}

Atualmente, um estudo (JARDIM; B.; J.A., 2009) mostrou os critérios para diagnóstico nos exames de espirometria, realizando uma análise de alguns parâmetros funcionais, ou marcadores, como o CVF, FEV1, etc.

Um método utilizado para diagnóstico da obstrução ou restrição de vias aéreas é o comparativo de valores encontrados no exame de espirometria, conforme figura 38 :

Figura 38 - Método de Diagnóstico na Espirometria

\begin{tabular}{|c|c|c|}
\hline Parâmetr ofuncional & Achado típico & Observação \\
\hline VEF1ICVF & $<0,70$ & Caracteriza a presença de obstruçã̃o \\
\hline VEF1 & $<80 \%$ previsto & Avalia a intensidade da doença \\
\hline CVF & $<70 \%$ previsto & Provável hiperinsuflaçẫo \\
\hline Prova broncodilatadora & $\begin{array}{l}\text { Negativa: VEF1 pós-bd com variação } \leq 12 \% \text { do } \\
\text { pré-bd } e<200 \mathrm{ml}\end{array}$ & Quando positiva pensarna possiblidade deasma \\
\hline VEF1ICVF & $\geq 0,70$ com CVF reduzida & Interrogar doença restritiva \\
\hline
\end{tabular}

Fonte: Jardim; B.; J.A., 2009.

Por fim, demonstramos que o nosso método proposto difere-se do método aplicado atualmente, pois apesar do método utilizado atualmente se basear em valores encontrados na realização do exame, o mesmo ainda padece de uma análise subjetiva e necessita da experiência médica para laudar o exame.

Alguns casos encontrados recebem um diagnóstico errôneo, pois se no momento do exame o indivíduo não cooperar ou não compreender a manobra espirométrica, o resultado final pode ser mal interpretado. Em todas as amostras que foram utilizadas neste estudo, foram 
executadas no mínimo quatro manobras ventilatórias durante a realização do exame, com o intuito de tentar eliminar essa variável indesejada.

Selecionamos as melhores manobras, através do próprio software do equipamento, mas ainda outras variáveis estão presentes, como possível falha na calibração do equipamento, mudança de temperatura ambiente, má compreensão do indivíduo na realização do exame, patologia em vias aéreas, como gripe ou resfriado, etc. Desta forma essas variáveis infligem diretamente no resultado do exame e não podem ser eliminadas em sua totalidade.

\subsection{ESTUDO DE CASO}

Durante a obtenção dos resultados de nosso estudo, uma das amostras apresentou uma diferenciação significativa, pois se tratava de um paciente diagnosticado como restritivo, mas que depois de uma análise mais aprofundada, e com a metodologia proposta por nós, obtivemos um resultado diferente do seu diagnóstico.

O exame realizado dentro de parâmetros normais, apresentou uma morfologia da curva de espirometria conforme a figura 39 :

Figura 39 - Tela do Software do Equipamento do Estudo de Caso

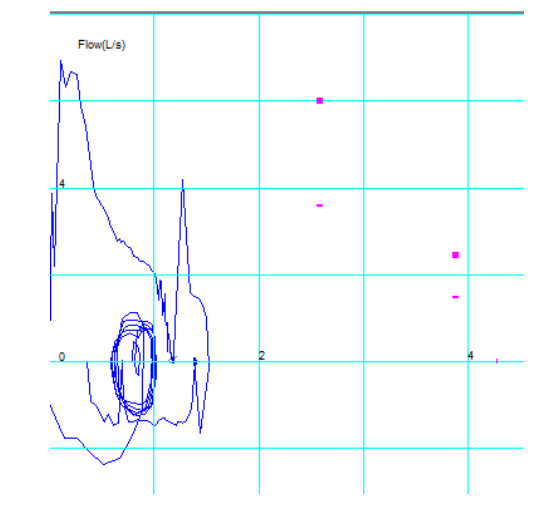

Fonte: Autor.

Assim, devido a uma má cooperação do paciente descrito na figura 40 no campo comentários, chegou-se a conclusão em diagnosticar o paciente como restritivo, através dos parâmetros encontrados durante o exame. A Figura 40 demonstra uma parte do laudo do exame onde é possível verificar os valores que são encontrados nos exames, bem como a relação com o previsto para associar e determinar o diagnóstico do exame.

Também é possível verificar que um dos métodos para se classificar o paciente em normal, obstrutivo e restritivo, o FEV1/CVF (mostrado como FEV1/FCV no exame) apresentou valor de $100 \%$, indicando um possível diagnóstico de normalidade no paciente.

Aplicando a nossa metodologia, conseguimos verificar o sinal do exame realizado, bem como a aplicação de nosso método, mostrado através das Figuras 41 e 42. 
Figura 40 - Tela do Laudo do Equipamento do Estudo de Caso

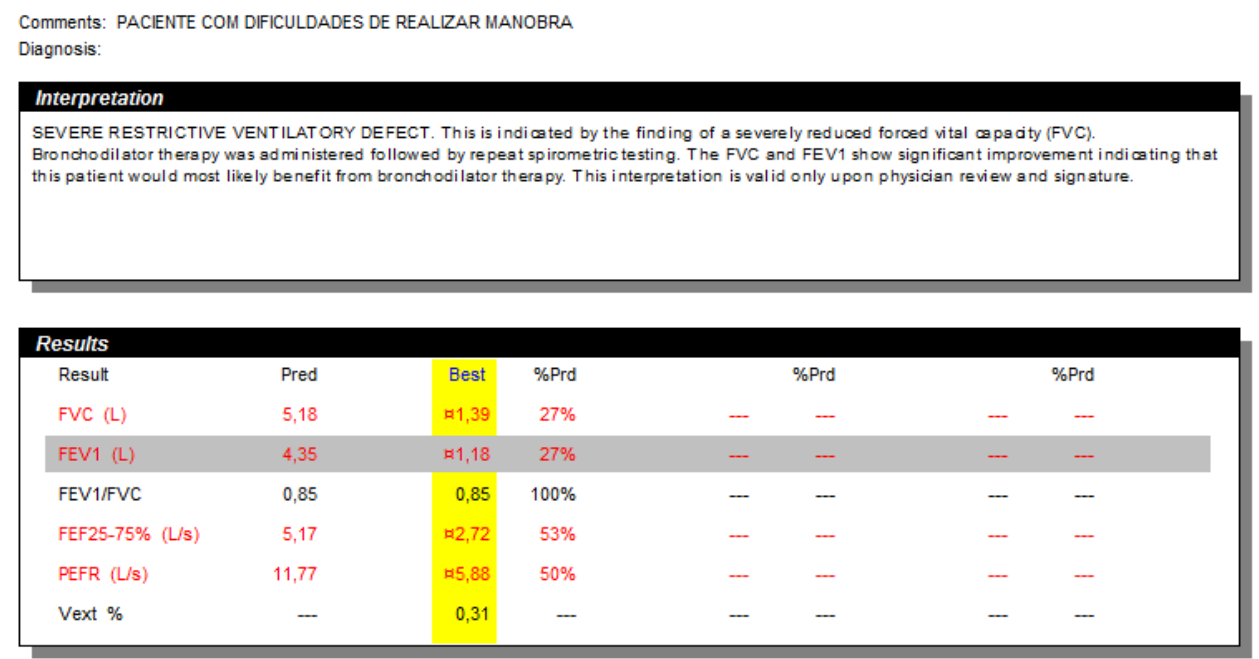

Fonte: Autor.

Figura 41 - Exportação dos Valores do Exame

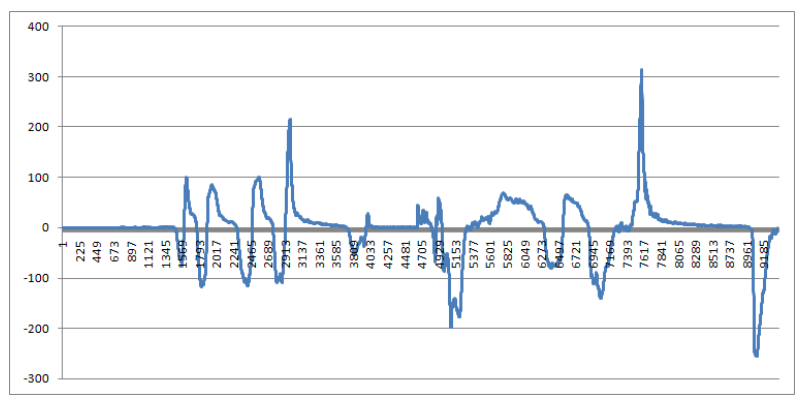

Fonte: Autor.

Figura 42 - Preparação para aplicação das wavelets

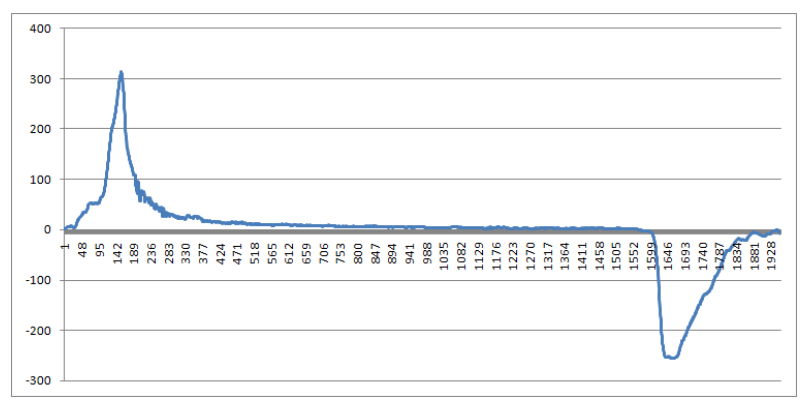

Fonte: Autor.

Após a aplicação das wavelets dentro do aplicativo matlab, encontramos os coeficientes que após a inserção em nosso estudo conseguimos analisar sua covariância em um valor de 1302,40, possibilitando um marcador adicional para este paciente em classificá-lo como normal.

Assim, durante esta análise, é possível afirmar que este paciente necessita de um estudo mais aprofundado e que talvez possa ter sido diagnosticado incorretamente, possivelmente 
por não colaborar na execução do exame de espirometria e pelo fato do técnico que diagnosticou o exame não possuir subsídios ou modelos matemáticos que dê embasamento na análise morfológica da curva do exame. 
Tabela 1 - Tabela do resultados de dados obtidos antes da aplicação das wavelets

\begin{tabular}{|c|c|c|c|c|c|c|c|c|}
\hline & & Indiv1 & Indiv2 & Indiv3 & $\ldots$ & Indiv6 & Indiv7 & Indiv8 \\
\hline \multirow{11}{*}{ 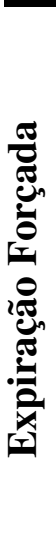 } & 1 & 34143,90 & 37324,92 & 40478,43 & $\ldots$ & 37436,41 & 41969,78 & 38738,39 \\
\hline & 2 & 33320,34 & 36410,71 & 39486,76 & $\ldots$ & 36352,80 & 40717,74 & 37595,90 \\
\hline & 3 & 33167,27 & 36241,26 & 39295,36 & $\ldots$ & 36378,29 & 40751,47 & 37620,96 \\
\hline & 4 & 32519,58 & 35523,09 & 38507,99 & $\ldots$ & 35615,74 & 39885,59 & 36849,04 \\
\hline & 5 & 31510,81 & 34404,48 & 37303,17 & $\ldots$ & 34227,36 & 38317,93 & 35378,79 \\
\hline & 6 & 31332,81 & 34207,12 & 37078,22 & $\ldots$ & 34239,90 & 38329,84 & 35394,36 \\
\hline & 7 & 30860,42 & 33683,47 & 36503,41 & $\ldots$ & 33778,75 & 37814,80 & 34948,54 \\
\hline & 8 & 29717,45 & 32415,87 & 35135,47 & $\ldots$ & 32149,50 & 35966,40 & 33208,22 \\
\hline & 9 & 29498,98 & 32173,69 & 34862,49 & $\ldots$ & 32101,11 & 35913,59 & 33175,27 \\
\hline & 10 & 29161,83 & 31799,96 & 34447,25 & $\ldots$ & 231865,45 & 35652,01 & 32963,78 \\
\hline & & $\ldots$ & $\ldots$ & $\ldots$ & $\ldots$ & $\ldots$ & $\ldots$ & $\ldots$ \\
\hline \multirow{22}{*}{ 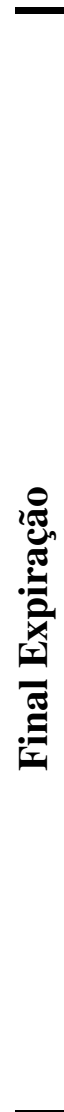 } & 800 & $-1,558$ & $-1,744$ & $-0,232$ & $\ldots$ & $-0,351$ & $-0,414$ & $-0,281$ \\
\hline & 801 & $-1,569$ & $-1,755$ & $-1,566$ & $\ldots$ & $-0,355$ & $-0,418$ & $-0,278$ \\
\hline & 802 & $-1,489$ & $-1,666$ & $-1,46$ & $\ldots$ & $-0,35$ & $-0,411$ & $-0,266$ \\
\hline & 803 & $-1,282$ & $-1,437$ & $-1,214$ & $\ldots$ & $-0,338$ & $-0,396$ & $-0,239$ \\
\hline & 804 & $-1,224$ & $-1,373$ & $-1,18$ & $\ldots$ & $-0,302$ & $-0,343$ & $-0,205$ \\
\hline & 805 & $-1,212$ & $-1,36$ & $-1,163$ & $\ldots$ & $-0,28$ & $-0,314$ & $-0,192$ \\
\hline & 806 & $-1,183$ & $-1,328$ & $-1,159$ & $\ldots$ & $-0,294$ & $-0,313$ & $-0,213$ \\
\hline & 807 & $-1,055$ & $-1,188$ & $-1,134$ & $\ldots$ & $-0,236$ & $-0,282$ & $-0,178$ \\
\hline & 808 & $-1,045$ & $-1,177$ & $-1,127$ & $\ldots$ & $-0,229$ & $-0,271$ & $-0,176$ \\
\hline & 809 & $-1,006$ & $-1,134$ & $-1,112$ & $\ldots$ & $-0,196$ & $-0,233$ & $-0,138$ \\
\hline & 810 & $-0,95$ & $-1,073$ & $-1,065$ & $\ldots$ & $-0,204$ & $-0,247$ & $-0,133$ \\
\hline & 811 & $-0,927$ & $-1,048$ & $-1,036$ & $\ldots$ & $-0,202$ & $-0,245$ & $-0,118$ \\
\hline & 812 & $-0,916$ & $-1,036$ & $-1,035$ & $\ldots$ & $-0,209$ & $-0,256$ & $-0,115$ \\
\hline & 813 & $-0,676$ & $-0,769$ & $-0,74$ & $\ldots$ & $-0,189$ & $-0,234$ & $-0,115$ \\
\hline & 814 & $-0,353$ & $-0,408$ & $-0,34$ & $\ldots$ & $-0,170$ & $-0,213$ & $-0,113$ \\
\hline & 815 & $-0,114$ & $-0,142$ & $-0,045$ & $\ldots$ & $-0,152$ & $-0,19$ & $-0,107$ \\
\hline & 816 & $-0,098$ & $-0,124$ & $-0,023$ & $\ldots$ & $-0,134$ & $-0,163$ & $-0,107$ \\
\hline & 817 & $-0,097$ & $-0,123$ & $-0,014$ & $\ldots$ & $-0,132$ & $-0,161$ & $-0,126$ \\
\hline & 818 & $-0,071$ & $-0,095$ & $-0,005$ & $\ldots$ & $-0,133$ & $-0,157$ & $-0,132$ \\
\hline & 819 & $-0,079$ & $-0,104$ & $-0,003$ & $\ldots$ & $-0,127$ & $-0,148$ & $-0,122$ \\
\hline & 820 & $-0,066$ & $-0,091$ & 0,008 & $\ldots$ & $-0,114$ & $-0,136$ & $-0,108$ \\
\hline & & $\ldots$ & $\ldots$ & $\ldots$ & $\ldots$ & $\ldots$ & $\ldots$ & $\ldots$ \\
\hline \multirow{11}{*}{ 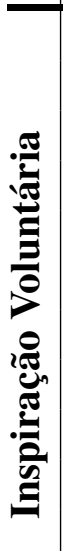 } & 1540 & 0,043 & 0,04 & $-0,032$ & $\ldots$ & $-0,042$ & $-0,022$ & $-0,021$ \\
\hline & 1541 & 0,043 & 0,04 & 0,05 & $\ldots$ & $-0,042$ & $-0,022$ & $-0,021$ \\
\hline & 1542 & 0,043 & 0,04 & 0,05 & $\ldots$ & $-0,042$ & $-0,022$ & $-0,021$ \\
\hline & 1543 & 0,043 & 0,04 & 0,05 & $\ldots$ & $-0,042$ & $-0,022$ & $-0,022$ \\
\hline & 1544 & 0,043 & 0,04 & 0,05 & $\ldots$ & $-0,042$ & $-0,022$ & $-0,021$ \\
\hline & 1545 & 0,043 & 0,04 & 0,05 & $\ldots$ & $-0,042$ & $-0,022$ & $-0,022$ \\
\hline & 1546 & 0,043 & 0,04 & 0,05 & $\ldots$ & $-0,042$ & $-0,022$ & $-0,022$ \\
\hline & 1547 & 0,043 & 0,04 & 0,05 & $\ldots$ & $-0,043$ & $-0,022$ & $-0,022$ \\
\hline & 1548 & 0,043 & 0,04 & 0,05 & $\ldots$ & $-0,042$ & $-0,022$ & $-0,022$ \\
\hline & 1549 & 0,043 & 0,04 & 0,05 & $\ldots$ & $-0,042$ & $-0,022$ & $-0,022$ \\
\hline & 1550 & 0,044 & 0,04 & 0,05 & $\ldots$ & $-0,042$ & $-0,022$ & $-0,022$ \\
\hline
\end{tabular}

Fonte: Autor. 
Tabela 2 - Valores obtidos após a aplicação de Wavelets de Meyer

\begin{tabular}{|c|c|c|c|c|c|c|c|c|c|}
\hline & & Indiv1 & Indiv2 & Indiv3 & Indiv4 & Indiv5 & Indiv6 & Indiv7 & Indiv8 \\
\hline \multirow{11}{*}{ 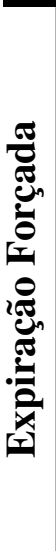 } & 1 & 335,15 & 510,88 & 3581,57 & $-410,85$ & $-92,74$ & 535,05 & 2118,96 & 1806,14 \\
\hline & 2 & 285,36 & $-35,21$ & 2191,34 & 209,54 & 150,41 & 46,58 & 984,10 & $-510,616$ \\
\hline & 3 & 371,84 & 340,05 & 3304,28 & $-105,24$ & 73,99 & 516,59 & 1896,03 & 1372,12 \\
\hline & 4 & 482,17 & 708,78 & 3600,53 & $-25,76$ & 211,68 & 858,08 & 2153,78 & 2353,13 \\
\hline & 5 & 238,47 & $-129,84$ & 2371,11 & 29,17 & 22,60 & $-17,69$ & 1122,24 & $-487,597$ \\
\hline & 6 & 361,91 & 299,47 & 3000,34 & $-3,68$ & 115,87 & 424,94 & 1649,57 & 950,17 \\
\hline & 7 & 483,62 & 704,64 & 3758,79 & $-73,39$ & 189,76 & 901,85 & 2282,93 & 2551,28 \\
\hline & 8 & 271,53 & $-9,29$ & 2491,75 & 33,70 & 54,18 & 88,79 & 1224,54 & $-158,59$ \\
\hline & 9 & 317,22 & 142,32 & 2774,87 & 9,35 & 82,80 & 266,16 & 1460,58 & 433,07 \\
\hline & 10 & 498,00 & 758,79 & 3805,35 & $-75,11$ & 200,43 & 940,12 & 2321,41 & 2678,43 \\
\hline & & $\ldots$ & $\ldots$ & $\ldots$ & $\ldots$ & $\ldots$ & $\ldots$ & $\ldots$ & $\ldots$ \\
\hline \multirow{22}{*}{ 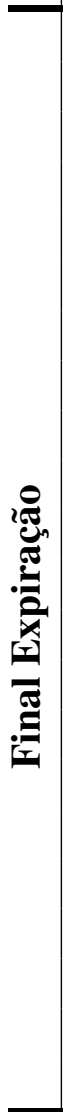 } & 800 & $-0,19$ & $-3,12$ & $-38,49$ & 1,69 & 3,87 & $-0,45$ & $-10,72$ & $-3,09$ \\
\hline & 801 & 11,76 & 6,71 & 41,45 & $-3,72$ & $-4,23$ & 0,86 & 4,89 & 10,03 \\
\hline & 802 & $-3,31$ & $-11,12$ & $-56,04$ & 4,57 & $-2,97$ & $-0,43$ & $-8,66$ & $-19,54$ \\
\hline & 803 & 7,24 & 22,04 & 19,08 & 2,91 & 8,09 & 1,81 & 8,74 & 20,36 \\
\hline & 804 & $-5,17$ & $-41,65$ & $-4,31$ & $-1,76$ & $-10,21$ & $-2,22$ & $-4,40$ & $-38,78$ \\
\hline & 805 & 15,45 & 86,76 & $-2,96$ & 4,00 & 9,22 & 16,18 & 5,49 & 62,40 \\
\hline & 806 & $-24,43$ & $-145,09$ & 15,43 & $-3,48$ & $-14,87$ & $-21,12$ & $-2,31$ & $-92,78$ \\
\hline & 807 & 1,60 & 9,78 & 8,39 & $-0,88$ & 3,94 & 0,57 & 4,98 & 26,32 \\
\hline & 808 & $-6,10$ & $-21,83$ & $-5,55$ & 1,82 & $-7,27$ & 1,71 & $-6,60$ & $-23,19$ \\
\hline & 809 & 2,64 & 7,09 & 29,61 & $-7,04$ & $-0,49$ & $-1,28$ & 5,51 & 19,06 \\
\hline & 810 & $-8,48$ & $-7,92$ & $-12,19$ & 9,32 & 4,40 & 1,44 & $-2,44$ & $-14,18$ \\
\hline & 811 & 1,16 & 7,66 & $-1,54$ & $-5,96$ & $-7,36$ & $-1,83$ & 5,59 & 5,83 \\
\hline & 812 & 5,69 & $-4,78$ & 99,45 & 4,55 & $-2,07$ & 4,56 & 12,76 & $-1,05$ \\
\hline & 813 & $-10,00$ & 3,07 & $-98,65$ & $-3,92$ & 2,13 & $-4,36$ & $-10,19$ & $-1,43$ \\
\hline & 814 & 1,19 & $-3,10$ & 59,71 & 4,54 & 6,80 & 2,21 & 6,02 & 2,53 \\
\hline & 815 & 1,61 & 1,21 & $-18,74$ & $-10,07$ & $-7,40$ & $-1,51$ & $-5,04$ & 2,92 \\
\hline & 816 & $-2,81$ & 3,50 & $-2,36$ & 7,07 & 6,02 & 0,38 & 2,48 & 1,89 \\
\hline & 817 & 3,21 & 16,46 & $-2,60$ & $-4,04$ & 2,81 & $-4,13$ & $-3,08$ & 0,20 \\
\hline & 818 & $-5,41$ & 13,42 & $-2,51$ & 0,02 & $-0,01$ & 0,77 & 1,24 & 16,74 \\
\hline & 819 & 3,79 & 11,18 & $-9,10$ & $-0,53$ & 6,18 & 1,90 & 3,00 & $-6,47$ \\
\hline & 820 & 10,19 & 49,38 & $-1,71$ & $-6,10$ & $-9,30$ & $-3,05$ & 4,21 & $-26,29$ \\
\hline & & $\ldots$ & $\ldots$ & $\ldots$ & $\ldots$ & $\ldots$ & $\ldots$ & $\ldots$ & $\ldots$ \\
\hline \multirow{11}{*}{ 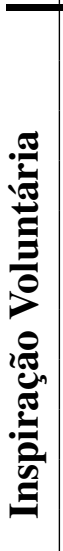 } & 1540 & 1,18 & 0,53 & $-1,74$ & $-0,083$ & $-0,24$ & $-0,26$ & $-0,04$ & 0,09 \\
\hline & 1541 & $-0,38$ & $-0,14$ & $-0,14$ & 0,78 & 0,36 & 0,02 & $-0,82$ & $-0,00$ \\
\hline & 1542 & 0,06 & 0,22 & $-0,00$ & 0,32 & 0,21 & $-0,25$ & 0,74 & $-0,21$ \\
\hline & 1543 & 0,17 & 0,22 & 0,45 & 0,18 & 0,23 & $-0,37$ & $-1,75$ & $-0,13$ \\
\hline & 1544 & $-0,38$ & $-0,14$ & $-1,03$ & $-0,35$ & $-0,01$ & 0,37 & 3,67 & $-0,43$ \\
\hline & 1545 & $-0,00$ & $-0,29$ & $-0,22$ & 0,58 & $-0,53$ & $-0,34$ & $-7,77$ & $-0,00$ \\
\hline & 1546 & $-0,32$ & $-0,39$ & 0,13 & $-0,06$ & 0,13 & $-0,51$ & 15,36 & $-0,00$ \\
\hline & 1547 & $-0,15$ & 0,04 & 0,62 & $-0,46$ & $-0,01$ & 1,16 & 1,85 & $-0,04$ \\
\hline & 1548 & $-0,36$ & $-0,03$ & $-0,44$ & $-0,35$ & 0,04 & 0,00 & $-3,47$ & 0,26 \\
\hline & 1549 & 0,60 & $-0,21$ & $-0,29$ & $-0,07$ & $-0,04$ & $-0,25$ & $-0,08$ & $-0,03$ \\
\hline & 1550 & $-0,02$ & $-0,28$ & 0,49 & 0,40 & 0,19 & $-0,43$ & $-0,37$ & 0,44 \\
\hline
\end{tabular}

Fonte: Autor. 
Tabela 3 - Valores de covariância e desvio padrão obtidos

Fonte: Autor.

\begin{tabular}{l|c|l}
\hline & MASCULINO & FEMININO \\
\hline Normal & $1079,38-1765,94$ & $984,70-1228,11$ \\
\hline Obstrutivo & $1876,54-2739,91$ & $1235,20-1402,54$ \\
\hline Restritivo & Acima de 3062,28 & Acima de 1392,23 \\
\hline
\end{tabular}

Tabela 4 - Tabela de Resultados Médios para Validação

\begin{tabular}{l|c|c|c|l}
\hline \multirow{2}{*}{} & \multicolumn{3}{|c}{ Resultados Obtidos Com a Metodologia Proposta } \\
\cline { 2 - 5 } & \multicolumn{2}{|c}{ Analisados } & \multicolumn{2}{c}{ Faixa Estimada de Referência } \\
\cline { 2 - 5 } & Masculino & Feminino & Masculino & Feminino \\
\hline Indivíduo Normal & 1734 & 1167 & $1079,38-1765,94$ & $984,70-1228,11$ \\
\hline Indivíduo Obstrutivo & 2527 & 1346 & $1876,54-2739,91$ & $1235,20-1402,54$ \\
\hline Indivíduo Restritivo & 5678 & 1873 & Acima de 3062,28 & Acima de 1392,23 \\
\hline
\end{tabular}
Fonte: Autor. 


\section{CONCLUSÃO}

Este trabalho procurou avaliar a possibilidade de aplicar wavelets com o intuito de caracterizar três parâmetros de avaliação em exames de espirometria. Testamos diferentes tipos de wavelets, como a wavelets de Deubechie, Haar e Meyer, obtendo sucesso na aplicação da wavelet de Meyer.

Como também testamos diversos níveis de detalhamento dos coeficientes, do nível 1 ao nível 5 em todos os modelos, pudemos observar qual teria melhor discrepância visual e assim obtivemos uma melhor aproximação dos coeficientes de detalhes para nossa análise estatística.

O resultado da análise indica que o método proposto para caracterização dos valores estudados permitiu, com sucesso realizar uma validação de doze amostras, permitindo a caracterização do resultado do exame dentro dos valores esperados. Foram utilizados quatro exames de características obstrutivas, quatro restritivas e quatro normais para os dois sexos, apresentando um valor de covariância dentro da faixa determinada.

Esses resultados indicam que a metodologia permite uma ferramenta adicional na detecção de patologias do sistema respiratório, sendo possível desde que efetuado corretamente o exame de espirometria, auxiliar no diagnóstico de alguma enfermidade.

Entretanto, como método para se diagnosticar alguma patologia pulmonar, podemos observar que são utilizados valores pontuais, como exemplo o FEV1 e CVF. No nosso estudo, usamos todos os pontos das curvas gráficas, uma diferença significativa que permitiu que nosso estudo resultasse em sucesso no seu modelo.

Nosso trabalho conseguiu obter a possibilidade de analisar a morfologia da curva de espirometria, propondo valores numéricos que puderam ser validados, dando subsídios ao profissional que irá diagnosticar o exame realizado.

É um marcador que irá auxiliar o médico para a validação do exame caso tenha valores dentro do previsto mas que por algum motivo como peso, altura, tabagismo e incompreensão no método da realização do exame, apresente um aspecto morfológico de sua curva espirométrica duvidosa.

\subsection{TRABALHOS FUTUROS}

Ampliar o estudo em diversas regiões mundiais.

Analisar a metodologia considerando idade, altura, peso e tabagismo com os resultados encontrados neste estudo.

Ampliar o estudo com a aplicação de bronco-dilatador nas vias aéreas.

Realizar um estudo com a metodologia proposta na detecção do paciente tossir durante a execução do exame.

Desenvolvimento de um "software"que utilize inteligência artificial afim de emitir um laudo que venha auxiliar o médico no seu diagnóstico. 


\section{REFERÊNCIAS}

ADELI, Hojjat; ZHOU, Ziqin; DADMEHR, Nahid. Analysis Of Eeg Records In An Epileptic Patient Using Wavelet Transform. Journal of Neuroscience Methods, v. 123, n. 1, p. 69-87, 2003.

AKAY, Metin. Wavelet applications in medicine. IEEE Spectrum, v. 34, n. 5, p. 50-56, 1997.

AKPINAR-ELCI, M.; FEDAN, K. B.; ENRIGHT, P. L. FEV6 as a surrogate for FVC in detecting airways obstruction and restriction in the workplace. European Respiratory Journal, v. 27, n. 2, p. 374-377, 2006.

ASHER, Rebecca J. Capnographic Analysis for Disease Classification by, 2012.

BELARDI, Aldo Artur; FAUSTO, Suzene. The Method of Moments and the Haar Wavelets Used in a Determination the Eddy Current Matrix. Journal of Electrical and Control Engineering, American V-King Scientific Publishing, v. 3, n. 4, 2013.

BETANCOURT, JP et al. Capnogram Feature Extraction Based on Wavelet Decomposition by Segments for Classification of Asthma Severity. ... Feature Extraction Based ..., p. 1-6, 2013.

BUSHA, Brett F. The Effect Of Wavelet-based Filtering And Data Set Length On The Fractal Scaling Of Cardiorespiratory Variability. 2010 Annual International Conference of the IEEE Engineering in Medicine and Biology Society, EMBC'10, p. 4546-4549, 2010.

CARTA, R. et al. A differential pressure approach to spirometry. Conference Proceedings IEEE Biomedical Circuits and Systems Conference Healthcare Technology, BiOCAS2007, p. 5-8, 2007.

CHEN, Shy-Leh; LIANG, Jin-Wei; HO, Keng-Chu. Parametric Identification of Nonlinear Systems by Haar Wavelets: Theory and Experimental Validation. Journal of Vibration and Acoustics, v. 134, n. 3, p. 031005, 2012.

COSTA, D; JARNARNI, E. Bases fundamentais da espirometria. Rev. bras. fisioter, v. 5, n. 2, p. 95-102, 2001.

DESHMUKH, Megha D.; PANDITRAO, Anagha. Design and development of thermistor based sensor for spirometry. 2012 IEEE Students' Conference on Electrical, Electronics and Computer Science: Innovation for Humanity, SCEECS 2012, p. 1-3, 2012. 
DEVI, G M.; VENKATESAN, P. Least Squares Support Vector Regression for Spirometric Forced Expiratory Volume (FEV1) Values. International Journal of Science and Technology, v. 3, n. 1, p. 74-78, 2013.

FERRARI, Hevelin Viviane; HOTO, Robinson; MACULAN, Nelson. Uma Comparação Entre Redes Neurais Wavelet, Lms , Mlp E Rbf Para Classificação De Dpoc. February 2016, 2006.

FINKELSTEIN, S.M. et al. Clinical staging of chronic rejection in lung transplantation using home spirometry. Annual International Conference of the IEEE Engineering in Medicine and Biology - Proceedings, v. 17, n. 1, p. 5-6, 1995.

GULDBRAND, Anna. A comparison of helium dilution and plethysmography in measuring static lung volumes. 2007. f. 54. Tese (Doutorado).

HANKINSON, John L.; GARDNER, Reed M. Standard waveforms for spirometer testing. Am Rev Respir Dis, n. 126, p. 362-364, 1982.

IRVIN, Charles; PH, D; MACINTYRE, Neil R. Medical Section of the American Lung Association. n. 7, p. 1-56, 1995.

JARDIM, J. R.; B., Pinheiro; J.A., Oliveira. Como Diagnosticar e Tratar Doença pulmonar obstrutiva crônica, p. 68, 2009.

KALICKA, Renata; SLOMINSKI, Wojcicch; KUZIEMSKI, Krzysztof. The modelling of spirometry - The application for diagnostic purposes. Proceedings of the 2008 1st International Conference on Information Technology, IT 2008, v. V, May, p. 1-3, 2008.

KASSEM, A.; HAMAD, M.; EL MOUCARY, C. A smart spirometry device for asthma diagnosis. Proceedings of the Annual International Conference of the IEEE Engineering in Medicine and Biology Society, EMBS, 2015-November, p. 1629-1632, 2015.

KAVITHA, A; SUJATHA, C M; RAMAKRISHNAN, S. Prediction of Spirometric Forced Expiratory Volume (FEV 1 ) Data Using Support Vector Regression. Measurement Science Review, v. 10, p. 63-67, 2010.

KHUBANI, J. Spirometric Data Analysis By Support Vector Machine, p. 2-5, 2012.

LABATE, Domenico et al. Empirical mode decomposition vs. wavelet decomposition for the extraction of respiratory signal from single-channel ECG: A comparison. IEEE Sensors Journal, v. 13, n. 7, p. 2666-2674, 2013. 
LADOSKY, Waldemar et al. Comparação entre valores espirométricos de referência obtidos a partir das equações de Knudson e de Pereira Adultos. Jornal de Pneumologia, v. 27, n. 6 , p. 315-320, 2001.

LAY-EKUAKILLE, A.; VENDRAMIN, G.; TROTTA, A. Spirometric measurement postprocessing: Expiration data recovery. IEEE Sensors Journal, v. 10, n. 1, p. 25-33, 2010.

LEE, Jungsil et al. Graphic analysis of flow-volume curves: a pilot study. BMC Pulmonary Medicine, BMC Pulmonary Medicine, v. 16, n. 1, p. 18, 2016.

LEWIS, BMl. Pitfalls of spirometry, p. 23-35, 1981.

LOPATA, V. et al. On the spirometry and spirometers standardization. 2013 IEEE 33rd International Scientific Conference Electronics and Nanotechnology, ELNANO 2013 Conference Proceedings, p. 316-318, 2013.

MAIA, Isabel A. Avaliação da função pulmonar por espirometria na leishmaniose visceral, 2015.

MEYER, Y. Wavelets-algorithms and applications. [S.l.: s.n.], 1993. p. 133.

MHETRE, Prof Manisha R; KHUBANI, Jitendra. Pattern Recognition and Forced Expiratory Volume (FEV1) Spirometric Data Prediction by Support Vector Machine. v. 28, p. 112-116, 2012.

MORETO TRINDADE, Alexandre; LINS FAGUNDES DE SOUSA, Thiago; LUIS PEREIRA ALBUQUERQUE, Andre. A interpretaçao da espirometria na pratica pneumologica: ate onde podemos avançar com o uso dos seus parametros? Pulmão RJ, v. 24, n. 1, p. 3-7, 2015.

MORETTIN, P.A. Ondas e Ondaletas. [S.1.: s.n.], 1999. p. 225.

MYTHILI, A; SUJATHA, C M. Analysis Of Spirometric Pulmonary Function Data Using Particle Swarm Optimization, 2015.

AL-NAAMI, Bassam et al. Utilizing wavelet transform and support vector machine for detection of the paradoxical splitting in the second heart sound. Medical and Biological Engineering and Computing, v. 48, n. 2, p. 177-184, 2010.

NGUYEN-KY, Tai et al. Measuring The Hypnotic Depth Of Anaesthesia Based On The EEG Signal Using Combined Wavelet Transform, Eigenvector And Normalisation Techniques.

Computers in Biology and Medicine, Elsevier, v. 42, n. 6, p. 680-691, 2012. 
PEREIRA, C. A. Espirometria. Jornal Brasileiro de Pneumologia, v. 28, supl 3, s1-s82, 2002.

PEREIRA, Carlos A. C. I Consenso Brasileiro sobre Espirometria. J Pneumol, v. 22, n. 3, p. 105-164, 1996.

PINHEIRO, Murilo Cerqueira et al. Comparação entre os valores de referência para CVF, VEF1 e relação VEF1 /CVF em brasileiros caucasianos adultos e aqueles sugeridos pela Global Lung Function Initiative 2012. v. 35, n. 12, p. 1168-1173, 2009.

RODRIGUES, Roberto Jr.; PEREIRA, Carlos A.C. Resposta a broncodilatador na espirometria : que parâmetros e valores são clinicamente relevantes em doenças obstrutivas? v. 27 , n. 1, p. 35-47, 2001.

RUPPEL, Gregg L; ENRIGHT, Paul L. Pulmonary Function Testing. Respiratory Care, v. 57, n. 1, p. 165-175, 2012.

SAHIN, Deniz et al. Diagnosis Of Airway Obstruction Or Restrictive Spirometric Patterns By Multiclass Support Vector Machines. Journal of Medical Systems, v. 34, n. 5, p. 967-973, 2010 .

SMITH, S J M. EEG in the diagnosis, classification, and management of patients with epilepsy. Journal of neurology, neurosurgery, and psychiatry, 76 Suppl 2, p. ii2-7, 2005.

SOLEIMANI, Vahid et al. Remote, Depth-based Lung Function Assessment. IEEE Transactions on Biomedical Engineering, v. X, n. 10, p. 1-1, 2016.

SPRIGGS, E A. The History Of Spirometry. British journal of diseases of the chest, v. 72, n. 3, p. 165-180, 1978.

TANK, Patrick W.; GEST, Thomas R. Atlas de Anatomia Humana. [S.1.: s.n.], 2009. v. 1.

TORTORA, Gerard J.; DERRICKSON, Bryan. Corpo Humano, Fundamentos de Anatomia e Fisiologia. [S.1.: s.n.], 2017. v. 1, p. 675.

ULBRICHT, Leandra. Análise da variância dos parâmetros de referência para classificação da função pulmonar. October, p. 2-6, 2016.

VALENTINUZZI, Max E.; JOHNSTON, Richard. Spirometry: A historical gallery up to 1905. IEEE Pulse, v. 5, n. 1, p. 73-76, 2014.

WANG, Xuewe. (2011). Event Detection For Post Lung Transplant Based On Home. 2011. Tese (Doutorado). 
ZEMLIN, W. R. Princípios De Anatomia e Fisiologia em Fonoaudiologia. [S.1.: s.n.], 2000. v. 1, p. 54-58.

ZHANG, Xuying; DENG, Caixia; HAN, Yao. The image space of meyer wavelet transform. Proceedings of 2013 2nd International Conference on Measurement, Information and Control, ICMIC 2013, v. 2, n. 50, p. 1136-1139, 2013. 
APÊNDICE A - ALGORITMO DE UTILIZAÇÃO PARA INSERÇÃO DOS DADOS NO MATLAB 


$$
\begin{aligned}
& \text { arqlnput = 'C: \teste \5.xIsx'; } \\
& \text { lev }=5 \text {; } \\
& \text { wname = 'dmey'; } \\
& \mathrm{nbcol}=64 \text {; } \\
& \text { tempo }=x \mid \text { sread }(\text { arq Input, 1,'BK5:B3835'); } \\
& \text { valores01 = xlsread(arqInput,1,'A5:A3835'); } \\
& \text { valores02 = xlsread(arqInput,1,'B5:B3835'); } \\
& \text { valores03 = xlsread (arqInput,1,'C5:C3835'); } \\
& \text { valores04 = xlsread(arqlnput,1,'D5:D3835'); } \\
& \text { valores05 = xlsread(arqInput,1,'E5:E3835'); } \\
& \text { valores06 = xlsread(arqInput,1,'F5:F3835'); } \\
& \text { valores07 = xlsread (arqInput,1, 'G5:G3835'); } \\
& \text { valores08 = xlsread(arqInput,1,'H5:H3835'); } \\
& \text { valores09 = xlsread (arqInput,1,'I5:I3835'); } \\
& \text { valores10 = xlsread(arqInput,1,'J5:J3835'); } \\
& \text { valores11 = xlsread(arqInput,1,'K5:K3835'); } \\
& \text { valores12 = xlsread(arqInput,1,'L5:L3835'); } \\
& \text { valores13 = xlsread(arqInput,1,'M5:M3835'); } \\
& \text { valores14 = xlsread(arqInput,1,'N5:N3835'); } \\
& \text { valores15 = xlsread(arqInput,1,'05:03835'); } \\
& \text { valores16 = xIsread(arqInput,1,'P5:P3835'); } \\
& \text { valores17 = xlsread(arqInput,1,'Q5:Q3835'); } \\
& \text { valores18 = xlsread(arqInput,1,'R5:R3835'); } \\
& \text { valores19 = xlsread (arqlnput,1,'S5:S3835'); } \\
& \text { valores20 = xlsread(arqlnput,1,'T5:T3835'); } \\
& \text { valores21 = xlsread(arqInput,1,'U5:U3835'); } \\
& \text { valores22 = xlsread (arqInput,1, 'V5:V3835'); } \\
& \text { valores23 = xlsread(arqInput,1,'W5:W3835'); } \\
& \text { valores24 = xlsread(arqInput,1,'X5:X3835'); } \\
& \text { valores25 = xlsread(arqInput,1,'Y5:Y3835'); } \\
& \text { valores26 = xlsread(arqInput,1,'Z5:Z3835'); } \\
& \text { valores27 = xlsread(arqInput,1, 'AA5:AA3835'); } \\
& \text { valores28 = xlsread(arqInput,1,'AB5:AB3835'); } \\
& \text { valores29 = xlsread (arqInput,1, 'AC5: AC3835'); } \\
& \text { valores30 = xlsread(arqInput,1,'AD5:AD3835'); } \\
& \text { valores31 = xlsread(arqInput,1,'AE5:AE3835'); } \\
& \text { valores32 = xlsread(arqInput,1,'AF5:AF3835'); } \\
& \text { valores33 = xlsread(arqInput,1,'AG5:AG3835'); } \\
& \text { valores34 = xlsread(arqInput,1,'AH5:AH3835'); } \\
& \text { valores35 = xlsread(arqInput,1,'AI5:Al3835'); } \\
& \text { valores36 = xIsread(arqInput,1,'AJ5:AJ3835'); }
\end{aligned}
$$




$$
\begin{aligned}
& \text { valores37 = xlsread(arqInput,1,'AK5:AK3835'); } \\
& \text { valores38 = xlsread(arqInput,1,'AL5:AL3835'); } \\
& \text { valores39 = xlsread(arqInput,1,'AM5:AM3835'); } \\
& \text { valores40 = xlsread(arqInput,1,'AN5:AN3835'); } \\
& \text { valores41 = xlsread (arqlnput,1,'AO5:A03835'); } \\
& \text { valores42 = xlsread(arqlnput,1,'AP5:AP3835'); } \\
& \text { valores43 = xlsread(arqlnput,1,'AQ5:AQ3835'); } \\
& \text { valores44 = xlsread(arqInput,1,'AR5:AR3835'); } \\
& \text { valores45 = xlsread(arqInput,1,'AS5:AS3835'); } \\
& \text { valores46 = xlsread(arqlnput,1,'AT5:AT3835'); } \\
& \text { valores47 = xlsread(arqInput,1,'AU5:AU3835'); } \\
& \text { valores48 = xlsread(arqInput,1,'AV5:AV3835'); } \\
& \text { valores49 = xlsread(arqInput,1,'AW5:AW3835'); } \\
& \text { valores50 = xlsread(arqInput,1,'AX5:AX3835'); } \\
& \text { valores51 = xlsread(arqInput,1,'AY5:AY3835'); } \\
& \text { valores52 = xlsread(arqInput,1,'AZ5:AZ3835'); } \\
& \text { valores53 = xlsread(arqInput,1,'BA5:BA3835'); } \\
& \text { valores54 = xlsread(arqlnput,1,'BB5:BB3835'); } \\
& \text { valores55 = xlsread(arqInput,1,'BC5:BC3835'); } \\
& \text { valores56 = xlsread (arqlnput,1,'BD5:BD3835'); } \\
& \text { valores57 = xlsread(arqInput,1,'BE5:BE3835'); } \\
& \text { valores58 = xlsread(arqInput,1,'BF5:BF3835'); } \\
& \text { valores59 = xlsread(arqInput,1,'BG5:BG3835'); } \\
& \text { valores60 = xlsread (arqlnput,1,'BH5:BH3835'); } \\
& \text { valores61 }=\text { xIsread (arqInput,1,'BI5:BI3835'); } \\
& \text { valores62 = xlsread(arqInput,1,'BJ5:BJ3835'); } \\
& {[\mathrm{c} 1, \mathrm{l1}]=\text { wavedec(valores01,lev,wname); }} \\
& {[c 2,12]=\text { wavedec(valores02,lev, wname); }} \\
& {[\mathrm{c3}, 13]=\text { wavedec(valores03,lev, wname); }} \\
& {[c 4,14]=\text { wavedec(valores04,lev,wname); }} \\
& {[\mathrm{c5}, 15]=\text { wavedec(valores05,lev,wname); }} \\
& {[c 6,16]=\text { wavedec(valores06,lev, wname); }} \\
& {[c 7,17]=\text { wavedec(valores07,lev,wname); }} \\
& {[c 8,18]=\text { wavedec(valores08,lev,wname); }} \\
& {[c 9,19]=\text { wavedec(valores09,lev, wname); }} \\
& {[c 10,110]=\text { wavedec(valores10,lev, wname); }} \\
& {[\mathrm{c} 11, \mathrm{l11}]=\text { wavedec(valores11,lev, wname); }} \\
& \text { [c12,l12] = wavedec(valores12,lev, wname); } \\
& {[c 13,113]=\text { wavedec(valores13,lev,wname); }} \\
& {[c 14, I 14]=\text { wavedec(valores14,lev, wname); }} \\
& {[c 15,115]=\text { wavedec(valores15,lev,wname); }}
\end{aligned}
$$


$[c 16, \mid 16]=$ wavedec(valores16,lev, wname);

$[c 17, \mid 17]=$ wavedec(valores17,lev,wname);

$[c 18,118]=$ wavedec(valores18,lev,wname);

$[c 19, \mid 19]=$ wavedec(valores19,lev, wname);

$[c 20,120]=$ wavedec $($ valores20,lev, wname $)$;

$[c 21,121]=$ wavedec $($ valores21,lev, wname);

[c22,122] = wavedec(valores22,lev, wname);

$[c 23,123]=$ wavedec(valores23,lev, wname);

$[c 24,124]=$ wavedec(valores24,lev, wname);

$[c 25,125]=$ wavedec(valores25,lev, wname);

[c26,126] = wavedec(valores26,lev,wname);

$[c 27,127]=$ wavedec(valores27,lev,wname);

$[c 28,128]=$ wavedec(valores28,lev, wname);

$[c 29,129]=$ wavedec(valores29,lev, wname);

$[c 30, \mid 30]=$ wavedec(valores30,lev, wname);

$[c 31, \mid 31]=$ wavedec(valores31,lev, wname);

$[c 32,132]=$ wavedec(valores32,lev, wname);

$[c 33,133]=$ wavedec(valores33,lev, wname);

$[c 34,134]=$ wavedec(valores34,lev,wname);

$[c 35,135]=$ wavedec(valores35,lev, wname);

$[c 36,136]=$ wavedec(valores36,lev, wname);

$[c 37,137]=$ wavedec $($ valores37,lev, wname);

$[c 38,138]=$ wavedec(valores38,lev, wname);

$[c 39,139]=$ wavedec(valores39,lev, wname);

$[c 40,140]=$ wavedec(valores40,lev, wname);

$[c 41,141]=$ wavedec(valores41,lev, wname);

[c42,142] = wavedec(valores42,lev, wname);

$[c 43,143]=$ wavedec(valores43,lev, wname);

$[c 44,144]=$ wavedec(valores44,lev, wname);

$[c 45,145]=$ wavedec(valores45,lev, wname);

$[c 46,146]=$ wavedec(valores46,lev, wname);

$[c 47,147]=$ wavedec(valores47,lev, wname);

$[c 48,148]=$ wavedec(valores48, lev, wname);

$[c 49,149]=$ wavedec(valores49,lev, wname);

$[c 50,150]=$ wavedec(valores50,lev, wname);

$[c 51,151]=$ wavedec(valores51,lev, wname);

$[c 52,152]=$ wavedec(valores52,lev, wname);

$[c 53,153]=$ wavedec(valores53,lev, wname);

$[c 54,154]=$ wavedec(valores54,lev, wname);

$[c 55,155]=$ wavedec(valores55,lev, wname);

$[c 56,156]=$ wavedec(valores56,lev, wname); 
$[\mathrm{c} 57,157]=$ wavedec(valores57,lev, wname);

$[c 58,158]=$ wavedec(valores58,lev,wname);

$[c 59,159]=$ wavedec(valores59,lev,wname);

$[c 60,160]=$ wavedec(valores60,lev, wname);

$[c 61,161]=$ wavedec(valores61,lev,wname);

$[c 62,162]=$ wavedec(valores62,lev, wname);

xlswrite('C: Iteste\testlab.xlsx',c1,1,'A1');

xlswrite('C: Iteste\testlab.xlsx',c2,1,'B1');

xlswrite('C: (teste (testlab.xIsx',c3,1,'C1');

xlswrite('C: Iteste\testlab.xlsx',c4,1,'D1');

xlswrite('C: (teste \testlab.xlsx',c5,1,'E1');

xlswrite('C: Iteste\testlab.xlsx',c6,1,'F1');

xlswrite('C: (testeltestlab.xlsx',c7,1,'G1');

xlswrite('C: Iteste\testlab.xlsx',c8,1,'H1');

xlswrite('C: \teste \testlab.xlsx',c9,1,'I1');

xlswrite('C: \teste\testlab.xlsx',c10,1,'J1');

xlswrite('C: Iteste Itestlab.xlsx',c11,1,'K1');

xlswrite('C: Iteste Itestlab.xlsx',c12,1,'L1');

xlswrite('C: Itesteltestlab.xlsx',c13,1,'M1');

xlswrite('C: Iteste (testlab.xIsx',c14,1,'N1');

xlswrite('C: Iteste Itestlab.xIsx',c15,1,'O1');

xlswrite('C: Iteste (testlab.xlsx',c16,1,'P1');

xlswrite('C: Iteste Itestlab.xIsx',c17,1,'Q1');

xlswrite('C: \teste \testlab.xIsx',c18,1,'R1');

xlswrite('C: \teste \testlab.xIsx',c19,1,'S1');

xlswrite('C: Iteste Itestlab.xlsx',c20,1,'T1');

xlswrite('C: Itesteltestlab.xlsx',c21,1,'U1');

xlswrite('C: \teste \testlab.xlsx',c22,1,'V1');

xlswrite('C: Iteste\testlab.xlsx',c23,1,'W1');

xlswrite('C: Iteste Itestlab.xlsx',c24,1,'X1');

xlswrite('C: \teste \testlab.xIsx',c25,1, 'Y1');

xlswrite('C: \teste (testlab.xlsx',c26,1,'Z1');

xlswrite('C: Iteste \testlab.xlsx',c27,1,'AA1');

xlswrite('C: teste\testlab.xlsx',c28,1,'AB1');

xlswrite('C: (teste) testlab.xlsx',c29,1,'AC1');

xlswrite('C: teste \testlab.xlsx',c30,1,'AD1');

xIswrite('C: (testeltestlab.xIsx',c31,1,'AE1');

xlswrite('C: teste \testlab.xlsx',c32,1,'AF1');

xlswrite('C: tteste Itestlab.xlsx',c33,1,'AG1');

xlswrite('C: teste \testlab.xlsx',c34,1,'AH1');

xlswrite('C: \teste (testlab.xIsx',c35,1,'Al1'); 
xlswrite('C: \teste\testlab.xIsx',c36,1,'AJ1');

xlswrite('C: Iteste \testlab.xIsx',c37,1,'AK1');

xlswrite('C: (teste\testlab.xIsx',c38,1,'AL1');

xlswrite('C: Itesteltestlab.xIsx',c39,1,'AM1');

xlswrite('C: \testeltestlab.xlsx',c40,1,'AN1');

xlswrite('C: Iteste \testlab.xIsx',c41,1,'AO1');

xlswrite('C: Iteste\testlab.xIsx',c42,1,'AP1');

xlswrite('C: Iteste \testlab.xIsx',c43,1,'AQ1');

xlswrite('C: (teste\testlab.xIsx',c44,1,'AR1');

xlswrite('C: Iteste \testlab.xIsx',c45,1,'AS1');

xlswrite('C: (teste \testlab.xIsx',c46,1,'AT1');

xlswrite('C: (teste\testlab.xIsx',c47,1,'AU1');

xlswrite('C: Itesteltestlab.xlsx',c48,1,'AV1');

xlswrite('C: Iteste Itestlab.xlsx',c49,1,'AW1');

xlswrite('C: Iteste \testlab.xIsx',c50,1,'AX1');

xlswrite('C: (teste (testlab.xIsx',c51,1,'AY1');

xlswrite('C: \teste\testlab.xIsx',c52,1,'AZ1');

xlswrite('C: (teste\testlab.xIsx',c53,1,'BA1');

xlswrite('C: \teste testlab.xIsx',c54,1,'BB1');

xlswrite('C: Iteste \testlab.xlsx',c55,1,'BC1');

xlswrite('C: Iteste testlab.xlsx',c56,1,'BD1');

xlswrite('C: Iteste (testlab.xIsx',c57,1,'BE1');

xlswrite('C: \teste \testlab.xIsx',c58,1,'BF1');

xlswrite('C: Iteste \testlab.xlsx',c59,1,'BG1');

xlswrite('C: (teste\testlab.xIsx',c60,1,'BH1');

xlswrite('C: Iteste \testlab.xlsx',c61,1,'BI1');

xlswrite('C: Iteste \testlab.xIsx',c62,1,'BJ1');

xlswrite('C: Iteste Itestlab.xlsx',I1,1,'BK1');

xlswrite('C: Iteste\testlab.xlsx',12,1,'BL1');

xlswrite('C: Iteste \testlab.xlsx',13,1,'BM');

xlswrite('C: Itesteltestlab.xIsx',14,1,'BN');

xlswrite('C: Itesteltestlab.xIsx',I5,1,'BO');

xlswrite('C: Iteste (testlab.xIsx',I6,1,'BP');

xlswrite('C: Iteste\testlab.xlsx',17,1,'BQ');

xlswrite('C: Iteste \testlab.xIsx',I8,1,'BR');

xlswrite('C: Iteste Itestlab.xlsx',19,1,'BS1');

xlswrite('C: Iteste (testlab.xIsx',I10,1,'BT1');

xlswrite('C: Iteste\testlab.xlsx',I11,1,'BU1');

xlswrite('C: Iteste \testlab.xIsx',I12,1,'BW1');

xlswrite('C: Iteste\testlab.xlsx',I13,1,'BX1');

xlswrite('C: Iteste\testlab.xIsx',I14,1,'BY1'); 
xlswrite('C: \teste \testlab.xlsx',I15,1,'BZ1');

xlswrite('C: Itesteltestlab.xlsx',I16,1,'CA1');

xlswrite('C: Iteste \testlab.xlsx',I17,1,'CB1');

xlswrite('C: Itesteltestlab.xlsx',I18,1,'CC1');

xlswrite('C: Iteste\testlab.xlsx',I19,1,'CD1');

xlswrite('C: \teste \testlab.xIsx',I20,1,'CE1');

xlswrite('C: tteste \testlab.xlsx',121,1,'CF1');

xlswrite('C: \teste\testlab.xIsx',I22,1,'CG1');

xlswrite('C: Iteste (testlab.xIsx',I23,1,'CH1');

xlswrite('C: teste\testlab.xlsx',124,1,'CI1');

xlswrite('C: Iteste (testlab.xlsx',125,1,'CJ1');

xlswrite('C: Iteste \testlab.xlsx',I26,1,'CK1');

xlswrite('C: Iteste (testlab.xlsx',127,1,'CL1');

xlswrite('C: Iteste\testlab.xlsx',I28,1,'CM1');

xlswrite('C: (teste\testlab.xIsx',I29,1,'CN1');

xlswrite('C: Iteste (testlab.xIsx',I30,1,'CO1');

xlswrite('C: Iteste \testlab.xIsx',I31,1,'CP1');

xlswrite('C: Iteste\testlab.xIsx',I32,1,'CQ1');

xlswrite('C: Iteste \testlab.xIsx',I33,1,'CR1');

xlswrite('C: Iteste (testlab.xlsx',134,1,'CS1');

xlswrite('C: \teste \testlab.xIsx',I35,1,'CT1');

xlswrite('C: (teste (testlab.xIsx',I36,1,'CU1');

xlswrite('C: Iteste\testlab.xIsx',I37,1,'CW1');

xlswrite('C: Itesteltestlab.xlsx',I38,1,'CX1');

xlswrite('C: Iteste (testlab.xlsx',139,1,'CY1');

xlswrite('C: Iteste \testlab.xlsx',140,1,'CZ1');

xlswrite('C: (teste\testlab.xIsx',141,1,'DA1');

xlswrite('C: Iteste (testlab.xIsx',142,1,'DB1');

xlswrite('C: (teste (testlab.xIsx',143,1,'DC1');

xlswrite('C: Iteste\testlab.xIsx',144,1,'DE1');

xlswrite('C: (teste\testlab.xIsx',145,1,'DF1');

xlswrite('C: \teste \testlab.xIsx',I46,1,'DG1');

xlswrite('C: (teste (testlab.xIsx',147,1,'DH1');

xlswrite('C: Iteste (testlab.xlsx',148,1,'DI1');

xlswrite('C: Iteste (testlab.xlsx',149,1,'DJ1');

xlswrite('C: Iteste\testlab.xlsx',I50,1,'DK1');

xlswrite('C: Iteste \testlab.xlsx',I51,1,'DL1');

xlswrite('C: (teste\testlab.xIsx',I52,1,'DM1');

xlswrite('C: Iteste \testlab.xIsx',I53,1,'DN1');

xlswrite('C: (teste\testlab.xIsx',154,1,'DO1');

xlswrite('C: (teste (testlab.xIsx',I55,1,'DP1'); 
xlswrite('C: Iteste \testlab.xlsx',I56,1,'DQ1');

xlswrite('C: Itesteltestlab.xlsx',I57,1,'DR1');

xlswrite('C: Iteste Itestlab.xlsx',I58,1,'DS1');

xlswrite('C:|testeltestlab.xlsx',I59,1,'DT1');

xlswrite('C: Iteste (testlab.xlsx',I60,1,'DU1');

xlswrite('C: Itesteltestlab.xlsx',I61,1,'DW1');

xlswrite('C: Iteste|testlab.xlsx',I62,1,'DX1'); 
APÊNDICE B - DADOS EXPORTADOS COMENTADOS 


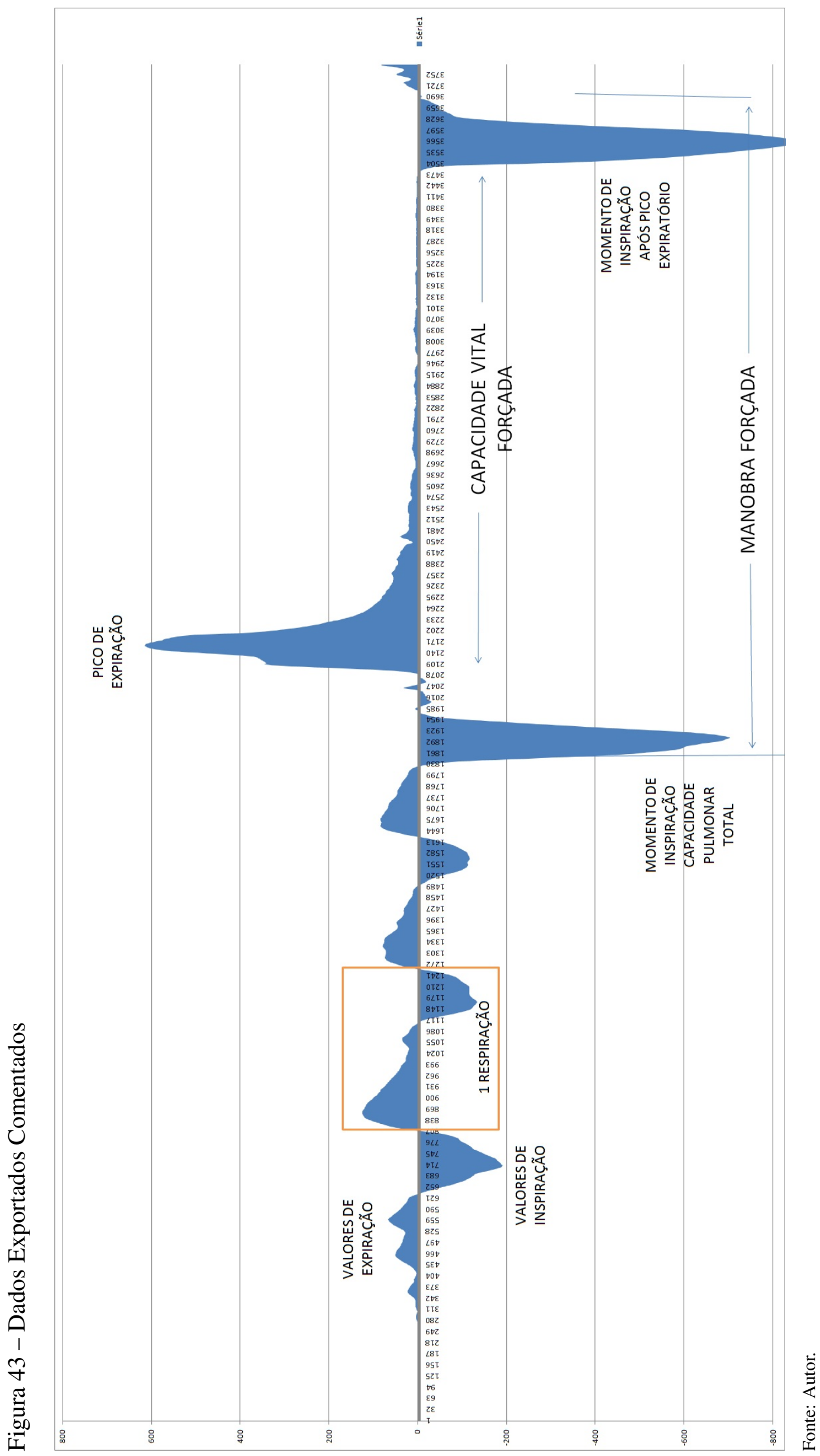


APÊNDICE C - AUTORIZAÇÃO DO USO DE BASE DE DADOS 


\section{TERMO DE CONFIDENCIALIDADE E AUTORIZAÇÃO DO USO DE INFORMAÇÕES}

Em 10 de Agosto de 2016, Eu, Dr. Jackson Gomes Marques, Médico Pneumologista credenciado pelo CRM sob o número 78176, após analise criteriosa dos documentos anexos a essa carta, constatei que são exames de função pulmonar, também conhecidas como espirometria simples, realizadas no período do ano de 2014.

Constato também que possui em seu conteúdo um breve cadastro para distinção, além de resultados dos exames considerados aceitáveis, além das curvas características de cada exame de fluxo x volume e volume x tempo (FxV e VxT) de cada indivíduo.

Autorizo o uso dessas informações, que fazem parte de meu arquivo pessoal, de forma confidencial, para serem utilizadas em pesquisa científica no âmbito acadêmico, como solicitado pelo Sr. Rodrigo Galuzzi Garcia Piva, aluno de Mestrado sob a orientação do Prof. Dr. Aldo Belardi com o tema ANÁLISE DE GRAFICOS ESPIROMÉTRICOS ATRAVÉS DA APLICAÇÃO DE WAVELETS, permitindo assim que a utilização desses exames realizados possam ser parte integrante de sua dissertação e levantamento de dados das curvas gráficas necessárias para sua pesquisa científica.

Sem Mais.

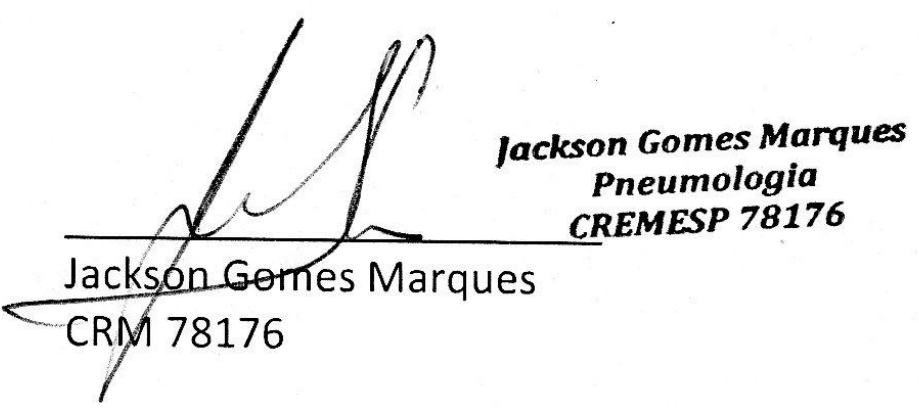




\section{Pulmonary Function Report}

Patient Information

Height at test (in): 68,5

Weight at test (lb): 160,6
Sex: Male

Age at test: 42
Smoking history (pk-yrs): 15

Predicted set: Pereira 2008 (Brazil)

\begin{tabular}{|c|c|c|c|c|c|c|c|}
\hline Result & Pred & Best & $\%$ Prd & & $\% \operatorname{Prd}$ & & $\% \operatorname{Prd}$ \\
\hline FVC (L) & 4,91 & 4,12 & $84 \%$ & 4,11 & $84 \%$ & 4,08 & $83 \%$ \\
\hline FEV1 (L) & 3,98 & 3,35 & $84 \%$ & 3,35 & $84 \%$ & 3,35 & $84 \%$ \\
\hline FEV1/FVC & 0,81 & 0,81 & $100 \%$ & 0,82 & $100 \%$ & 0,82 & $101 \%$ \\
\hline FEF25-75\% (L/s) & 3,79 & 3,66 & $97 \%$ & 3,68 & $97 \%$ & 3,81 & $100 \%$ \\
\hline PEFR (L/s) & 11,23 & $a 6,74$ & $60 \%$ & a 7,28 & $65 \%$ & a6,59 & $59 \%$ \\
\hline Vext $\%$ & -- & 6,59 & --- & 4,38 & --- & 4,16 & -- \\
\hline
\end{tabular}

\section{FVC Flow vs. Volume}

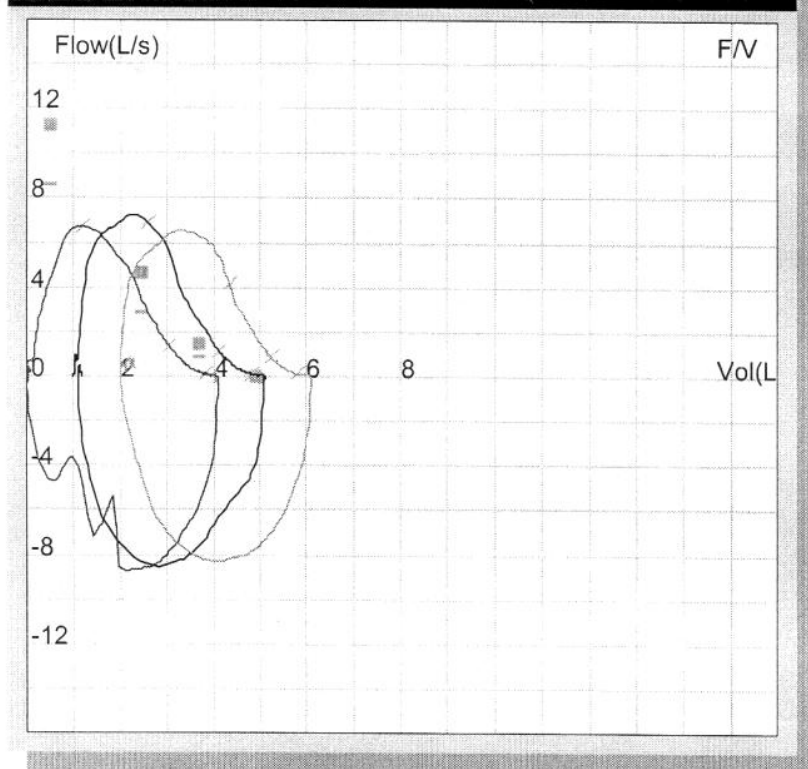

\section{FVC Volume vs. Time}

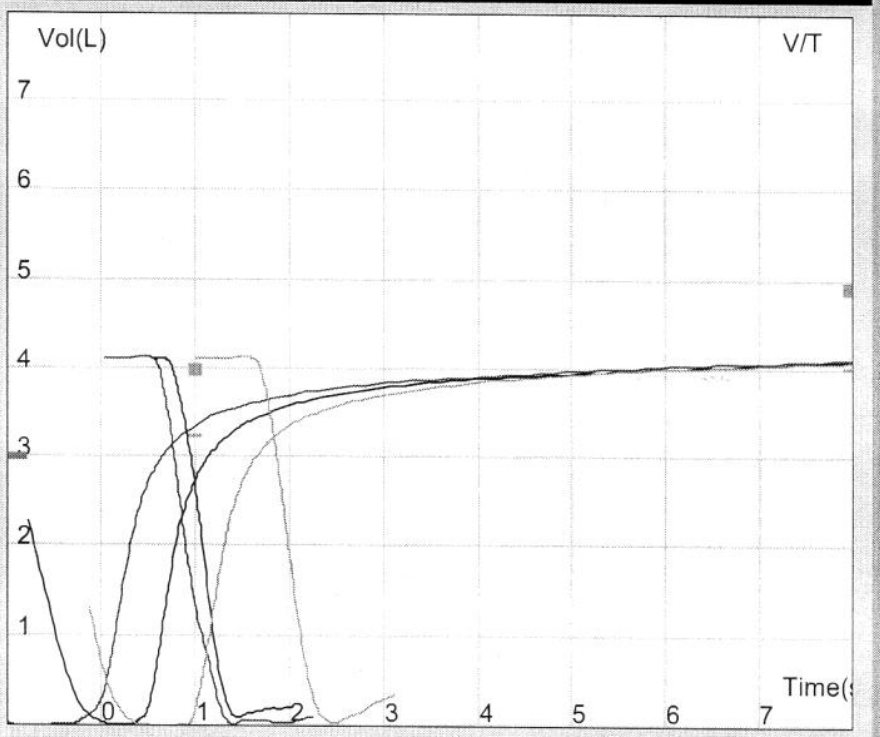




\section{Pulmonary Function Report}

Patient Information

Height at test (in): 62,2

Weight at test (lb): 169,4
Sex: Female

Age at test: 30
Smoking history (pk-yrs): 0

Predicted set: Pereira 2008 (Brazil)

\begin{tabular}{|c|c|c|c|c|c|c|c|}
\hline Result & Pred & Best & $\%$ Prd & & $\%$ Prd & & $\%$ Prd \\
\hline FVC (L) & 3,52 & $\not 2,81$ & $80 \%$ & $\approx 2,76$ & $79 \%$ & 42,76 & $79 \%$ \\
\hline FEV1 (L) & 2,96 & $\square 1,99$ & $67 \%$ & 21.97 & $67 \%$ & 무 1,88 & $64 \%$ \\
\hline FEV1/FVC & 0,84 & $\square 0,71$ & $84 \%$ & $\square 0,72$ & $85 \%$ & ㅁ0,68 & $81 \%$ \\
\hline FEF25-75\% (L/s) & 3,20 & $\times 1,37$ & $43 \%$ & a 1,41 & $44 \%$ & a1,22 & $38 \%$ \\
\hline PEFR (L/s) & 7,42 & $a 4,88$ & $66 \%$ & $\square 4,39$ & $59 \%$ & $\square 3,70$ & $50 \%$ \\
\hline Vext \% & --- & 2,93 & --- & 3,43 & --- & 3,16 & --- \\
\hline
\end{tabular}

\section{FVC Flow vs. Volume}

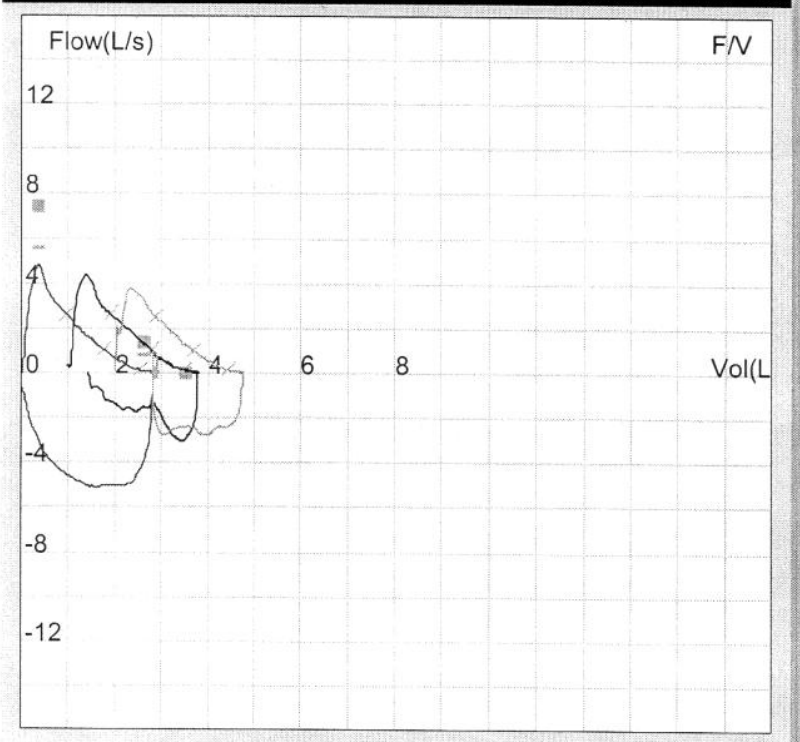

\section{FVC Volume vs. Time}

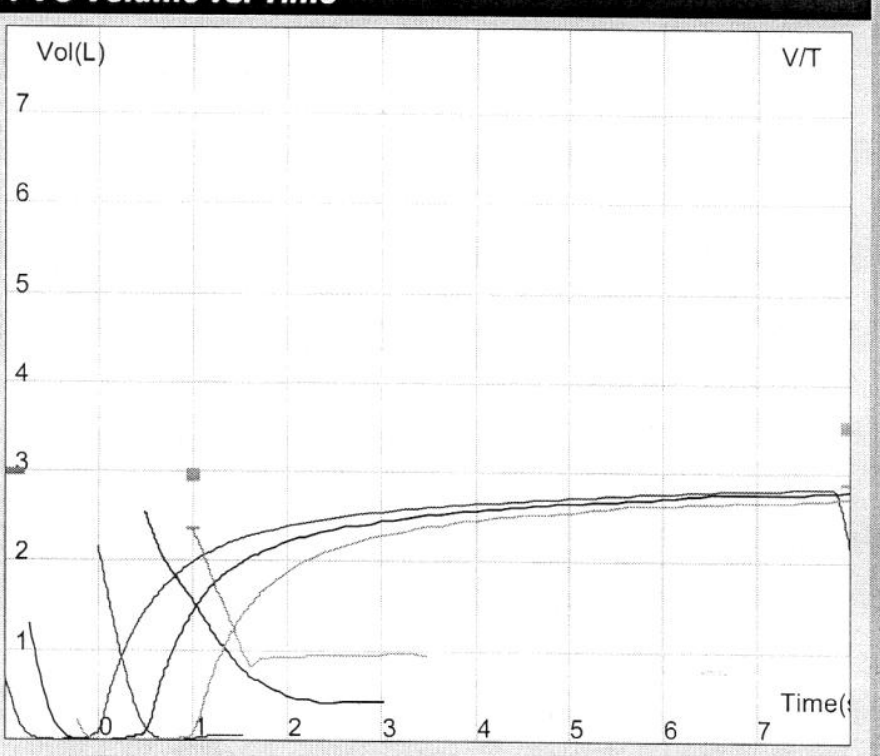

